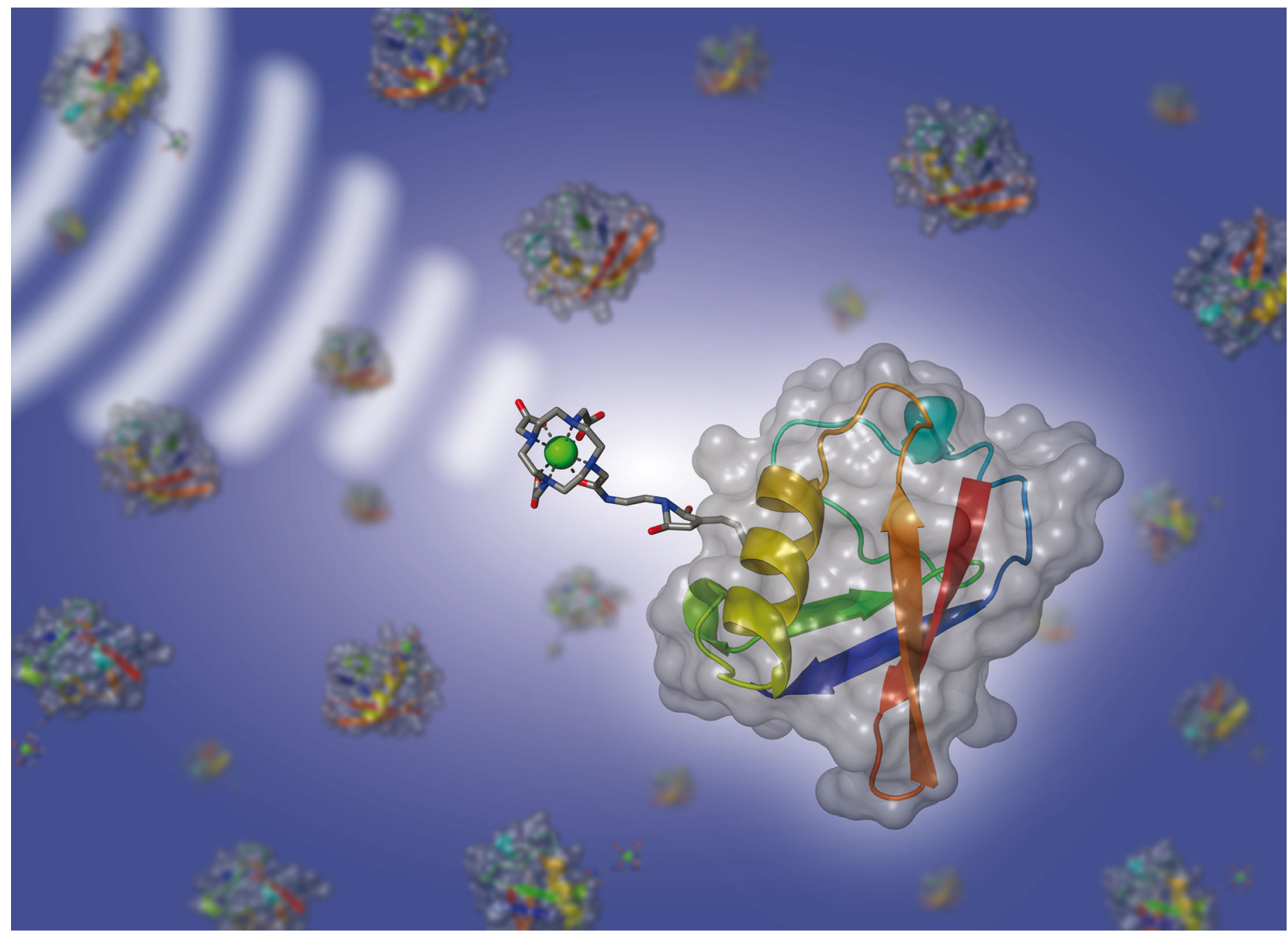

Showcasing work from the laboratories of Dr Björn Corzilius and collaborators at Goethe University Frankfurt and Massachusetts Institute of Technology.

Title: Gd(III) and $\mathrm{Mn}(\mathrm{II})$ complexes for dynamic nuclear polarization: small molecular chelate polarizing agents and applications with site-directed spin labeling of proteins

In this work paramagnetic ions of $\mathrm{Gd}(\mathrm{III})$ and $\mathrm{Mn}$ (II) are investigated as polarizing agents for sensitivity enhancement of solid-state magic-angle spinning (MAS) NMR by dynamic nuclear polarization (DNP). Signal enhancement factors of up to 136-fold are reported at a magnetic field of $9.4 \mathrm{~T}$. Chelate complexes of these ions can be dissolved in the sample, or can be attached to proteins for targeted DNP as is shown in the above illustration for ubiquitin. The paper investigates several experimental scenarios and is accompanied by a detailed theoretical derivation of the underlying mechanisms (B. Corzilius, Phys. Chem. Chem. Phys., 2016, DOI: 10.1039/c6cp04621e).

\section{As featured in:}

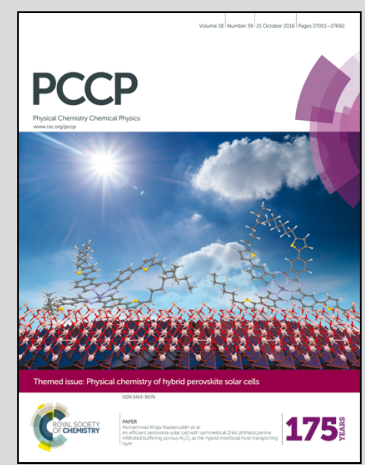

See Björn Corzilius et al.,

Phys. Chem. Chem. Phys., 2016, 18, 27205.

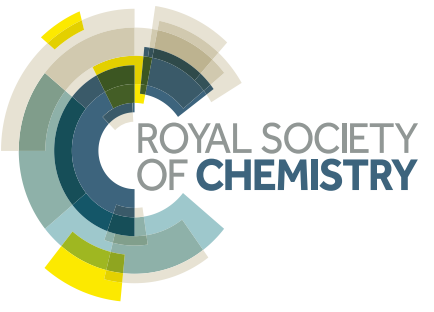




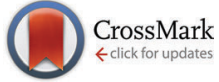

Cite this: Phys. Chem. Chem. Phys., 2016, 18, 27205

Received 2nd July 2016 Accepted 12th August 2016

DOI: $10.1039 / c 6 c p 04623 a$

www.rsc.org/pccp

\title{
Gd(III) and $M n$ (II) complexes for dynamic nuclear polarization: small molecular chelate polarizing agents and applications with site-directed spin labeling of proteins $\dagger$
}

\author{
Monu Kaushik, ${ }^{\text {ab }}$ Thorsten Bahrenberg, $\ddagger^{\mathrm{ab}}$ Thach V. Can, ${ }^{\mathrm{c}}$ Marc A. Caporini, $\S^{\mathrm{d}}$ \\ Robert Silvers, ${ }^{\text {bce }}$ Jörg Heiliger, ${ }^{\text {ab }}$ Albert A. Smith, $q^{c}$ Harald Schwalbe, ${ }^{\text {be }}$ \\ Robert G. Griffin ${ }^{\mathrm{C}}$ and Björn Corzilius*abc
}

\begin{abstract}
We investigate complexes of two paramagnetic metal ions $\mathrm{Gd}^{3+}$ and $\mathrm{Mn}^{2+}$ to serve as polarizing agents for solid-state dynamic nuclear polarization (DNP) of ${ }^{1} \mathrm{H},{ }^{13} \mathrm{C}$, and ${ }^{15} \mathrm{~N}$ at magnetic fields of $5,9.4$, and 14.1 T. Both ions are half-integer high-spin systems with a zero-field splitting and therefore exhibit a broadening of the $m_{\mathrm{S}}=-1 / 2 \leftrightarrow+1 / 2$ central transition which scales inversely with the external field strength. We investigate experimentally the influence of the chelator molecule, strong hyperfine coupling to the metal nucleus, and deuteration of the bulk matrix on DNP properties. At small Gd-DOTA concentrations the narrow central transition allows us to polarize nuclei with small gyromagnetic ratio such as ${ }^{13} \mathrm{C}$ and even ${ }^{15} \mathrm{~N}$ via the solid effect. We demonstrate that enhancements observed are limited by the available microwave power and that large enhancement factors of $>100$ (for ${ }^{1} \mathrm{H}$ ) and on the order of 1000 (for ${ }^{13} \mathrm{C}$ ) can be achieved in the saturation limit even at $80 \mathrm{~K}$. At larger Gd(III) concentrations $\left(\geq 10 \mathrm{mM}\right.$ ) where dipolar couplings between two neighboring $\mathrm{Gd}^{3+}$ complexes become substantial a transition towards cross effect as dominating DNP mechanism is observed. Furthermore, the slow spin-diffusion between ${ }^{13} \mathrm{C}$ and ${ }^{15} \mathrm{~N}$, respectively, allows for temporally resolved observation of enhanced polarization spreading from nuclei close to the paramagnetic ion towards nuclei further removed. Subsequently, we present preliminary DNP experiments on ubiquitin by site-directed spinlabeling with $\mathrm{Gd}^{3+}$ chelator tags. The results hold promise towards applications of such paramagnetically labeled proteins for DNP applications in biophysical chemistry and/or structural biology.
\end{abstract}

\section{Introduction}

\section{Dynamic nuclear polarization}

\footnotetext{
${ }^{a}$ Institute of Physical and Theoretical Chemistry and Institute of Biophysical Chemistry, Goethe University Frankfurt, Max-von-Laue-Str. 7-9, 60438 Frankfurt am Main, Germany. E-mail: corzilius@em.uni-frankfurt.de

${ }^{b}$ Center for Biomolecular Magnetic Resonance (BMRZ), Goethe University Frankfurt, Max-von-Laue-Str. 9, 60438 Frankfurt am Main, Germany

${ }^{c}$ Francis Bitter Magnet Laboratory and Department of Chemistry,

Massachusetts Institute of Technology, 77 Massachusetts Avenue, Cambridge, Massachusetts 02139, USA

${ }^{d}$ Bruker Biospin Ltd., Billerica, Massachusetts 01821, USA

${ }^{e}$ Institute of Organic Chemistry and Chemical Biology, Goethe University Frankfurt, Max-von-Laue-Str. 7, 60438 Frankfurt am Main, Germany

$\dagger$ Electronic supplementary information (ESI) available. See DOI: 10.1039/с6ср04623a \$ Present address: Department of Chemical Physics, Weizmann Institute of Science, 76100 Rehovot, Israel.

$\S$ Present address: Amgen, Inc., 360 Binney Street, Cambridge, Massachusetts 02142 , USA.

I Present address: Department of Chemistry and Applied Biosciences, Laboratory

of Physical Chemistry, ETH-Zürich, CH-8093 Zürich, Switzerland.
}

Over the last two decades high field dynamic nuclear polarization (DNP) has emerged as a prominent field of research and has impacted approaches to solution NMR, solid-state or magic-angle spinning (MAS) NMR, electron paramagnetic resonance (EPR), and magnetic resonance imaging (MRI). Furthermore, DNP has spawned fundamental investigations and new applications in each of these areas. For example, the development of the instrumentation for MAS DNP at high magnetic fields ${ }^{1-4}$ has catalyzed fundamental studies of quantum mechanical properties of spin-systems, ${ }^{5-14}$ applications in materials science ${ }^{15-20}$ and structural biology. ${ }^{21-30}$

\section{DNP polarizing agents and field profiles}

Paramagnetic species act as polarizing agents by transferring the large electron spin polarization to nuclear spins upon irradiation with microwaves $(\mu \mathrm{w})$ of an appropriate frequency. 

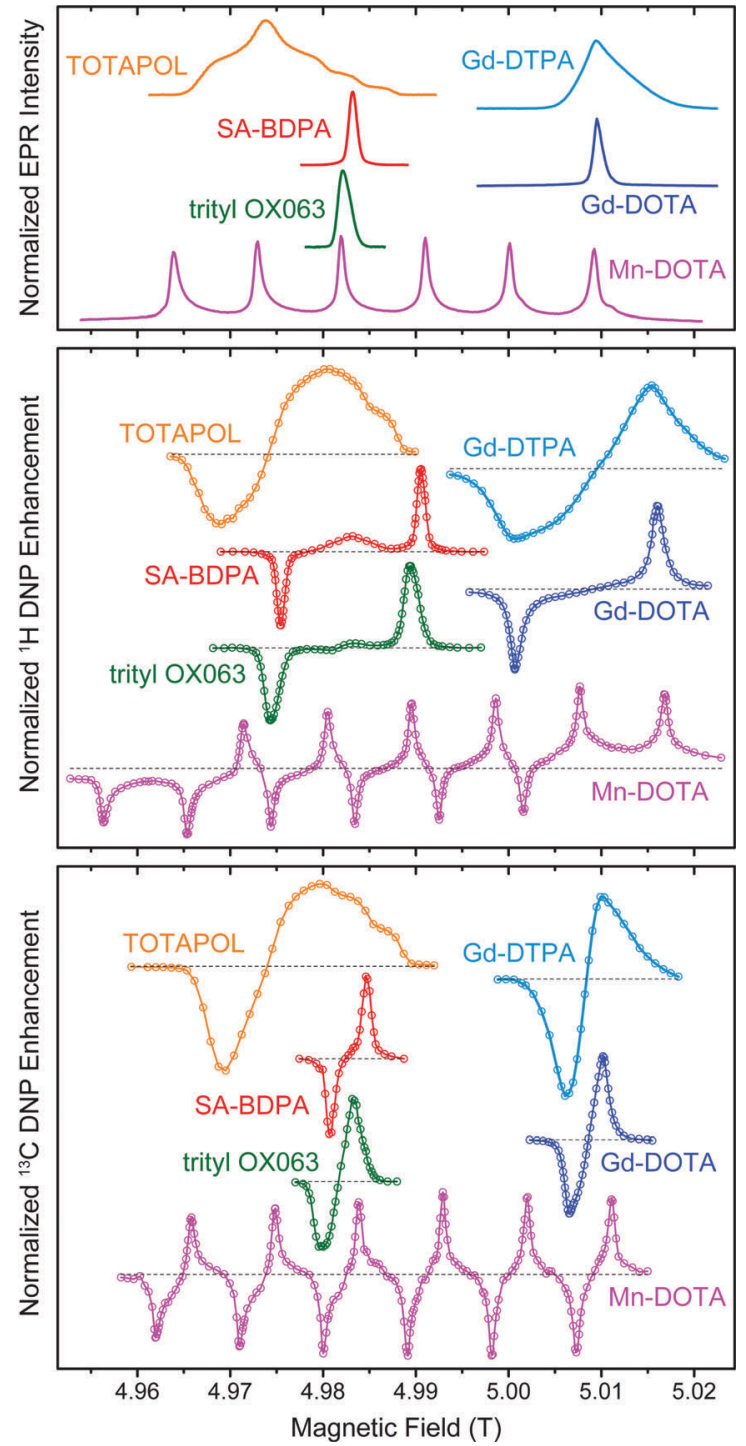

Fig. 1 EPR spectra (top) as well as field-dependent ${ }^{1} \mathrm{H}$ (middle) and ${ }^{13} \mathrm{C}$ (bottom) DNP profiles of various polarizing agents at $140 \mathrm{GHz} \mu \mathrm{w}$ frequency. TOTAPOL DNP data taken from ref. $32\left({ }^{1} \mathrm{H}\right)$ and $33\left({ }^{13} \mathrm{C}\right)$. SA-BDPA and trityl OX063 data from ref. 34 and 35 , respectively, except ${ }^{13} \mathrm{C}$ DNP profiles which were taken from ref. 36. Gd(II) and $M n(I)$ EPR spectra taken from ref. 37; DNP data from this work.

Microwave radiation is generated by either a solid-state source or-in the case of MAS DNP-by a gyrotron maser source due to the high power requirement in the absence of a $\mu \mathrm{w}$ resonance structure. ${ }^{31}$ Since gyrotrons typically emit a fixed, narrow-band frequency the NMR magnetic field has to be adjusted if polarizing agents with varying EPR resonance fields are to be used or investigated.

In Fig. 1 we give an overview of several polarizing agents representing different classes of paramagnetic substances. TOTAPOL $^{32}$ is one of the most prominent examples of bisnitroxide biradicals $\mathrm{s}^{38,39}$ which allow for efficient cross effect (CE) DNP of ${ }^{1} \mathrm{H}$ and ${ }^{13} \mathrm{C}^{33}$ Trityl OX063 ${ }^{40}$ and SA-BDPA ${ }^{34}$ are watersoluble, persistent organic (carbon-based) radicals with rather narrow EPR resonances. At $5 \mathrm{~T}$ the linewidth of trityl $(\sim 50 \mathrm{MHz})$ only allows for the solid effect (SE) of ${ }^{1} \mathrm{H}$ with $212 \mathrm{MHz}$ Larmor frequency, ${ }^{35,41}$ while the smaller frequency of ${ }^{13} \mathrm{C}(53 \mathrm{MHz})$ leads to efficient CE. ${ }^{7,36}$ For SA-BDPA with $28 \mathrm{MHz}$ linewidth both nuclei can only be polarized via the SE. ${ }^{34,36}$ Paramagnetic metal complexes of $\mathrm{Gd}^{3+}$ and $\mathrm{Mn}^{2+}$ have been demonstrated as polarizing agents for ${ }^{1} \mathrm{H}$ DNP earlier; ${ }^{37}$ recently we have shown that $\mathrm{Mn}^{2+}$ naturally bound to RNA can be used to hyperpolarize ${ }^{13} \mathrm{C}$ within a nucleic acid complex. ${ }^{42}$ Even though the enhancement factors cannot compete quantitatively with the highly efficient bis-nitroxides, the natural occurrence in metalloproteins-in the case of $\mathrm{Mn}^{2+}$ - or the possibility to replace diamagnetic metal ions such as $\mathrm{Mg}^{2+}$ or $\mathrm{Ca}^{2+}$ make these high-spin metal ions interesting targets for further research.

\section{DNP with intrinsic polarizing agents}

One aspect that has become of particular interest is the incorporation of polarizing agent with respect to the analyte. In "conventional" studies the polarizing agent-consisting of a paramagnetic molecule and providing the large electron polarization to be transferred to the nuclear spins-is dissolved in a cryoprotecting matrix. The matrix is highly deuterated with reduced proton abundance of $\sim 10 \%$ in order to optimize signal enhancement factors and transfer of enhanced polarization to the analyte via spin-diffusion. ${ }^{43}$ This method has been successfully applied to several biological sample systems, including membrane proteins in native phospholipid environments as well as liposomes, ${ }^{22,26,44,45}$ and dispersed micro- $/$ nano-crystalline proteins and peptides or amyloid fibrils. ${ }^{25,46-48}$ A similar approach is used for microcrystalline materials ${ }^{49}$ or by impregnation wetting of insoluble materials with polarizing agent solutions for surface-enhanced NMR spectroscopy. ${ }^{17}$

Immobilized paramagnetic species being covalently or noncovalently bound to or near the biomolecule to be investigated have recently attracted interest. In a first and elegant demonstration an endogenous flavin in its reduced semiquinone radical form has been used to polarize ${ }^{1} \mathrm{H}$ within the protein. ${ }^{50}$ Besides circumventing the addition of a solvent matrix and potential phase separation, ${ }^{51-54}$ this approach is also aimed towards more efficient utilization of enhanced nuclear polarization near the site of interest at high magnetic field and fast MAS where spin-diffusion efficiency is limited ${ }^{55}$ and towards further structural insights by analysis of site- or state-specific DNP enhancement. ${ }^{56,57}$ Furthermore, we have shown that endogenously bound, diamagnetic metal ions can be substituted with paramagnetic analogs in order to allow for DNP of ribonucleic acids. $^{42}$

\section{Paramagnetic metal chelates in magnetic resonance}

$\mathrm{Gd}(\mathrm{III})$ and $\mathrm{Mn}$ (II) chelate complexes are currently in the focus of several magnetic resonance techniques, including their use as efficient contrast agents in magnetic resonance imaging (MRI). ${ }^{58-61}$ Spin labels based on Gd(III) have been demonstrated for distance measurements by dipolar EPR spectroscopy. ${ }^{62-69}$ Additionally, both $\mathrm{Mn}^{2+}$ and $\mathrm{Gd}^{3+}$ have been used to study metal binding to biomolecules by paramagnetic relaxation enhancement of nuclear spins in solution NMR. ${ }^{70,71}$ Similarly both ions 
have been artificially attached to proteins by site-directed spin labeling with chelators for determination of structural constraints; ${ }^{72,73}$ such applications have been demonstrated for magic-angle spinning (MAS) NMR as well. ${ }^{74,75}$ Additionally, covalent labeling with $\mathrm{Mn}$ (II) or Gd(III) chelates allows for distance measurements by dipolar EPR spectroscopy. ${ }^{62,63,65,68,69}$ Due to their chemical stability under redox-active conditions these complexes have proven extremely interesting for the investigation of in-cell EPR spectroscopy, ${ }^{67}$ where nitroxide radicals suffer from chemical inactivation $^{76,77}$ and in-cell applications demand additional precautions. ${ }^{78,79}$ Given these prospects in combination with the ubiquitous use of lanthanide chelate tags in NMR and the large availability of respective labeling techniques ${ }^{80}$ we have earlier investigated the use of Mn(II) and Gd(III) chelate model compounds as polarizing agents for sensitivity-enhanced MAS NMR using dynamic nuclear polarization (DNP) of ${ }^{1} \mathrm{H}$ at a field of $5 \mathrm{~T} \cdot{ }^{37} \mathrm{Here}$, we want to extend this investigation to fields of $9.4 \mathrm{~T}$ and up to 14.1 T. Furthermore, we focus on direct DNP of low- $\gamma$ nuclei ${ }^{13} \mathrm{C}$ and ${ }^{15} \mathrm{~N}$ for which slower spin-diffusion might enable a siteselective DNP enhancement of resonances in biomolecules which contain a specifically-bound metal polarizing agent. Preliminary experiments obtained with chelator-labeled and uniformly isotope labeled ubiquitin yield promising results.

\section{Theory}

\section{DNP mechanisms}

Under the conditions relevant here DNP can occur via two different mechanisms: solid effect (SE) and cross effect (CE). SE enhancements are driven directly by $\mu \mathrm{w}$ excitation of nominally forbidden zero quantum (ZQ) and double quantum (DQ) electronnuclear coherences. ${ }^{81}$ Anisotropic hyperfine interaction (HFI) leads to partial state mixing of the nuclear substates; the respective ZQ and DQ SE matching conditions occur at the sum or difference combinations of the electron and nuclear Larmor frequencies. Due to the ZQ and DQ transitions leading to opposite nuclear enhancement and cancellation of the SE when excited equally, the polarizing agent has to feature a narrow EPR spectrum with an effective overall breadth smaller than the nuclear Larmor frequency.

The CE occurs when two electron spins are dipolar coupled. Upon $\mu \mathrm{w}$ saturation of one of the spins their polarization difference can be transferred to a coupled nuclear spin if the Larmor frequencies of the electron spins differ by the nuclear Larmor frequency: $\Delta \omega_{0 S}=\omega_{0 I}{ }^{82}$ In this case an energy-conserving three-spin flip-flop-flip process can occur. This process has been shown to be highly efficient for bis-nitroxide polarizing agents under MAS, where the variation in electron Larmor frequencies is achieved by significant $g$ anisotropy, and the spin eigenstates undergo several level crossings during one sample rotational period. ${ }^{12,13}$

In the preceding article we have described the theoretical background in detail and have developed a model for CE with high-spin electrons with isotropic electron Zeeman interaction and significant ZFS such as Gd(III) and Mn(II). ${ }^{83}$ We strongly encourage the reader to refer to this work for theoretical background as basis of discussion of the experiments described here.

\section{Magnetic properties of Gd(III) and Mn(II)}

The high-spin states of Gd(III) and Mn(II) lead to several peculiar properties which can be either advantageous or detrimental for applications in magnetic resonance. We have described these properties in detail in the preceding article; ${ }^{83}$ nevertheless we want to briefly summarize these here. Even though the electron Zeeman interaction is isotropic with a $g$ value close to that of the free electron the $S=7 / 2$ and $S=5 / 2$ states of $\operatorname{Gd}($ III) and $\mathrm{Mn}$ (II), respectively, are subject to zero-field splitting (ZFS) most commonly caused by non-cubic ligand environment. In typical complexes this leads to an anisotropic broadening of the satellite transitions (ST) - where $m_{S}$ changes its absolute value-by up to several $\mathrm{GHz}$ in total breadth. Due to the half-integer spin state a narrow central transition (CT)-where $\left|m_{S}\right|$ is conserved-is observed which is not affected by ZFS in first-order; however, a second-order broadening occurs if the ZFS parameters are of significant magnitude with respect to the Zeeman splitting. Furthermore, $\mathrm{Mn}$ (II) underlies strong isotropic hyperfine interaction (HFI) to its core ${ }^{55} \mathrm{Mn}$ nucleus $(I=5 / 2)$ with typical coupling constants $\sim 250 \mathrm{MHz}$, leading to a characteristic sextet pattern in EPR spectra. For Gd(III) small HFI to the minority magnetic nuclei ${ }^{157} \mathrm{Gd}$ and ${ }^{159} \mathrm{Gd}$ (both $I=3 / 2$ and $15 \%$ abundance each) can be neglected in most cases.

\section{Experimental}

\section{EPR}

Pulsed EPR spectra at $140 \mathrm{GHz}$ and $275 \mathrm{GHz}$ have been recorded using custom-built EPR spectrometers at a temperature of $80 \mathrm{~K}$. Spectra were acquired by recording the field-swept intensity of a Hahn-echo of frozen solutions of each polarizing agent in $1 \mathrm{mM}$ concentration in $\mathrm{D}_{8}$-glycerol/ $\mathrm{D}_{2} \mathrm{O}(60 / 40 \mathrm{vol} \%)$ mixture. Detailed descriptions of the instruments can be found elsewhere. ${ }^{84-86}$

Continuous-wave EPR spectra of Gd(III)-labeled protein (see below) have been recorded using a Bruker EleXsys E780 spectrometer operating at $263 \mathrm{GHz}$ and utilizing a sweepable Bruker Ascent DNP magnet $(89 \mathrm{~mm})$ centered at 9.40 $\mathrm{T}$ and contained a superconducting sweep coil with a nominal range of $\pm 75 \mathrm{mT}$. The Bruker magnet power supply is remotely controlled by the Bruker Xepr software used for data acquisition. The spinlabeled proteins were dissolved at concentrations between 2 and $4 \mathrm{mM}$ in a $\mathrm{D}_{8}$-glycerol/ $\mathrm{D}_{2} \mathrm{O} / \mathrm{H}_{2} \mathrm{O}(60 / 30 / 10$ vol\%) mixture, packed into $0.2 \mathrm{~mm}$ (i.d.) clear fused quartz capillaries and frozen inside a custom-built $\mathrm{TE}_{011}$ resonator. Experiments were performed at a temperature of $100 \mathrm{~K}$ inside an Oxford instruments flow cryostat using liquid Helium as cryogen. For detailed set of parameters see ESI. $\dagger$

\section{DNP at $5 \mathrm{~T}(140 \mathrm{GHz})$}

DNP experiments at $5 \mathrm{~T}$ were performed on samples containing 10 mM Gd-DOTA (Macrocyclics, Dallas, TX), Gd-DTPA (gracious gift of E. Ravera and C. Luchinat, Florence), or $\mathrm{GdCl}_{3}$ (Sigma-Aldrich, 
St. Louis, MO) in a ${ }^{13} \mathrm{C}_{3}$-glycerol/ $\mathrm{H}_{2} \mathrm{O}\left(60 / 40\right.$ vol\%) or a $\left[\mathrm{D}_{8},{ }^{13} \mathrm{C}_{3}\right]$ glycerol $/ \mathrm{D}_{2} \mathrm{O} / \mathrm{H}_{2} \mathrm{O}(60 / 30 / 10 \mathrm{vol} \%)$ mixture. ${ }^{13} \mathrm{C}$-labeled glycerol was purchased from Cambridge Isotope Laboratories (Tewksbury, MA). All compounds were used as received without further purification. The custom-built spectrometer operating at $213 \mathrm{MHz}{ }^{1} \mathrm{H}$ frequency is courtesy of $\mathrm{D}$. Ruben. A custom-built MAS NMR probe was utilized which features a triple resonance $\mathrm{rf}$ circuit $\left({ }^{1} \mathrm{H},{ }^{13} \mathrm{C},{ }^{15} \mathrm{~N}\right)$ and efficient microwave coupling to the sample using overmoded corrugated waveguides (similar to a design published by Barnes et al. ${ }^{87}$ ). The probe was also equipped with a cryogenic sample exchange system. Microwaves were generated using a custom-built gyrotron oscillator operating at $139.65 \mathrm{GHz}$ with a maximum output power of $\sim 13 \mathrm{~W}^{2,31,88}$ Sample temperature was measured via a fiber optical sensor (Neoptix, Québec City, Canada) outside the MAS stator and was maintained at about $84 \mathrm{~K}$. Experiments were performed using a MAS frequency of $\omega_{\mathrm{r}} / 2 \pi=5 \mathrm{kHz}$. A detailed description of experiments is given in the ESI. $\dagger$

\section{DNP at 9.4 T (263 GHz) and above}

The comparison of ${ }^{1} \mathrm{H}$ DNP at 9.4 $\mathrm{T}$ and $14.1 \mathrm{~T}$ was performed at Bruker BioSpin (Billerica, MA) on two different DNP/NMR spectrometers operating at $400 \mathrm{MHz} / 263 \mathrm{GHz}$ and $600 \mathrm{MHz} /$ $395 \mathrm{GHz}$, respectively. The sample contained $10 \mathrm{mM}$ Gd-DOTA and $100 \mathrm{mM}\left[{ }^{13} \mathrm{C},{ }^{15} \mathrm{~N}\right]$-proline dissolved in $\mathrm{D}_{8}$-glycerol $/ \mathrm{D}_{2} \mathrm{O}$ / $\mathrm{H}_{2} \mathrm{O}(60 / 30 / 10$ vol\%). The spectrometers are equipped with $3.2 \mathrm{~mm} \mathrm{H}-\mathrm{X}$ probes of which the $\mathrm{X}$ channels are tuned to ${ }^{13} \mathrm{C}$. The ${ }^{13} \mathrm{C}$ NMR signals of proline were measured by CP pulse sequence with a pre-saturation period. The temperature of the sample was $\sim 90 \mathrm{~K}$ without microwave and $\sim 100 \mathrm{~K}$ with $\sim 15 \mathrm{~W}$ of microwave. The sample was spun at $\omega_{\mathrm{r}} / 2 \pi=12.5 \mathrm{kHz}$.

All other DNP experiments at 9.4 T were performed using a commercially available Bruker AVANCE III DNP spectrometer operating at $401.7 \mathrm{MHz}{ }^{1} \mathrm{H}$ frequency. $2 \mathrm{M}\left[{ }^{13} \mathrm{C},{ }^{15} \mathrm{~N}_{2}\right]$-urea (CortecNet) was dissolved in a glass forming solvent of $\left[\mathrm{D}_{8},{ }^{12} \mathrm{C}_{3}\right]$-glycerol/ $\mathrm{H}_{2} \mathrm{O}$ (60/40 vol\%). The glycerol depleted in ${ }^{13} \mathrm{C}\left(99.95 \%{ }^{12} \mathrm{C}\right)$ was purchased from Euriso-Top. Gd-DOTA- $\mathrm{NH}_{3}$ (gracious gift of J. Plackmeyer, Frankfurt) was used as polarizing agent in concentrations of $2 \mathrm{mM}, 10 \mathrm{mM}$ and $20 \mathrm{mM}$. All compounds were used as purchased without further purification. A Bruker gyrotron yielding $263.4 \mathrm{GHz}$ microwaves, operating at the maximum beam current of $115 \mathrm{~mA}$ was used. ${ }^{1} \mathrm{H}$ enhancement was recorded using cross-polarization to ${ }^{13} \mathrm{C}$. Direct ${ }^{13} \mathrm{C}$ and ${ }^{15} \mathrm{~N}$ enhancements were measured using Bloch decay. Microwave on and off experiments were performed at $114 \mathrm{~K}$ and $105 \mathrm{~K}$ respectively; this temperature was measured outside the stator. Sample heating due to $\mu \mathrm{w}$ irradiation was not quantified or controlled for. MAS of $8 \mathrm{kHz}$ was employed. For further information see ESI. $\dagger$

\section{Protein expression and labeling}

A detailed description of protein expression, purification, and labeling is given in the ESI. $\dagger$ 4-Mercaptomethyl dipicolinic acid (4MMDPA) has been synthesized following the procedure published by Potapov et al. ${ }^{63}$ 1,4,7,10-tetraazacyclododecane1,4,7-tris-acetic acid-10-maleimidoethylacetamide (DOTA-M) was purchased from Macrocyclics, Inc. (Plano, TX). After recombinant expression, purification, labeling, and concentration, the uniformly $\left[{ }^{13} \mathrm{C},{ }^{15} \mathrm{~N}\right]$-labeled protein was transferred to an $\mathrm{NH}_{4} \mathrm{OAc}$ buffer $(\mathrm{pH}=7.0)$ for DNP with a final concentration of $\sim 1 \mathrm{mM}$ ubiquitin in $60 \%(\mathrm{v} / \mathrm{v})\left[\mathrm{D}_{8},{ }^{12} \mathrm{C}_{3}\right]$-glycerol, $36 \% \mathrm{D}_{2} \mathrm{O}$, and $4 \%$ $\mathrm{H}_{2} \mathrm{O}$. The labeling efficiency was quantified using cw spincounting at $\mathrm{X}$-band frequency at $80 \mathrm{~K}$ and was determined as $\sim 90 \%$ in the case of $4 \mathrm{MMDPA}$ and $\sim 100 \%$ for DOTA-M.

\section{Results and discussion}

\section{EPR linewidth of the CT at different fields}

With the introduction of several custom-built or commercially available DNP spectrometers operating at fields between 9.4 and $18.8 \mathrm{~T}$ considerable focus should be laid on the efficiency of polarizing agents with increasing fields. One important aspect in this context is the broadening of the EPR line and resulting excitation efficiency with a monochromatic microwave source.

In Fig. 2 we demonstrate the effect of increasing external magnetic field strength on the line shape of several polarizing agents with narrow EPR lines which have been utilized for SE at high field. While SA-BDPA shows no significant variation in linewidth between $140 \mathrm{GHz}$ (5 T) and $275 \mathrm{GHz}$ (9.8 T) due to negligible $g$-anisotropy and inhomogeneous broadening dominated by unresolved hyperfine couplings to ${ }^{1} \mathrm{H}$, the axially symmetric $g$-anisotropy of trityl leads to an increase of spectral
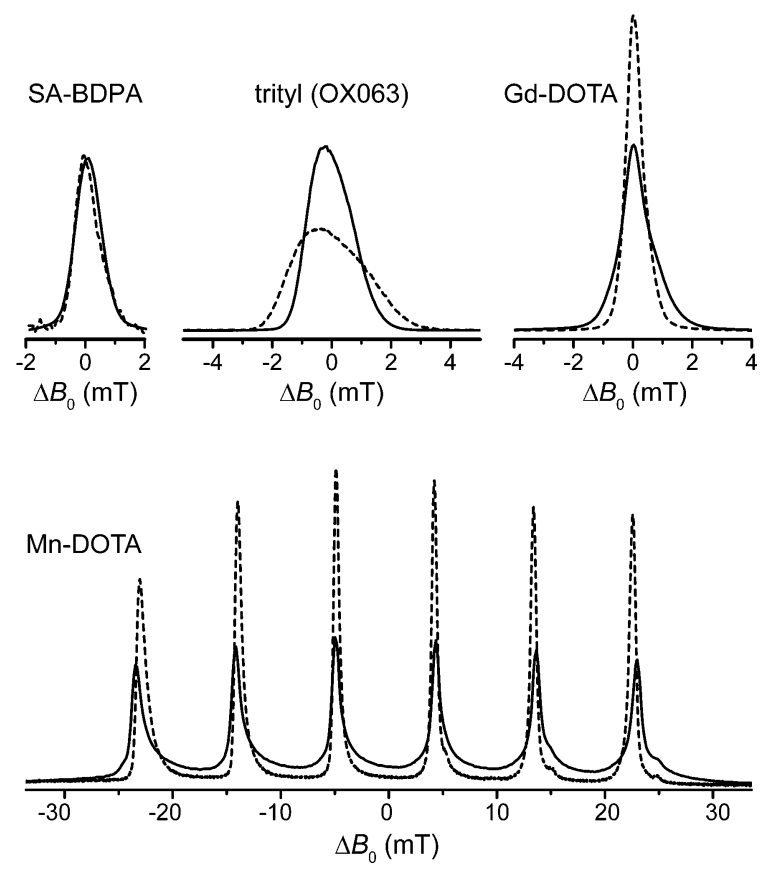

Fig. $2140 \mathrm{GHz}$ (solid lines) and $275 \mathrm{GHz}$ (dashed lines) field-swept, echo-detected EPR spectra of SA-BDPA, trityl, Gd-DOTA, and Mn-DOTA demonstrating the narrowing of the high-spin $\mathrm{CT}$ at higher field. All spectra (except $\mathrm{Mn}$-DOTA) were normalized to equal amplitude at $140 \mathrm{GHz}$. All $275 \mathrm{GHz}$ spectra were scaled so that the respective integrals at the two frequencies are equal. Field offset in abscissa is given w.r.t. to the resonance field observed for the isotropic $g$ value. 
breadth proportional to the external field. The high-spin complexes of $\mathrm{Gd}^{3+}$ and $\mathrm{Mn}^{2+}$, on the other hand, show an effective reduction in linewidth of the EPR CT with higher field which seems counterintuitive at first, but is explained by the occurrence of a second-order effect due to ZFS which scales inversely proportional with respect to the Zeeman strength. In the preceding article we have described in detail the unique properties of these high-spin metal ions regarding DNP; ${ }^{83}$ here we will demonstrate these properties in DNP experiments performed on ${ }^{1} \mathrm{H}$ and ${ }^{13} \mathrm{C}$ at a field of $5 \mathrm{~T}$. Further experiments conducted at high fields of 9.4 $\mathrm{T}$ and $14.1 \mathrm{~T}$ demonstrate the unique linenarrowing properties of Gd-DOTA and underline the potential of this class of polarizing agents under these high-field conditions, especially when compared to the efficiency of the SE with radical polarizing agents at these high field strengths. ${ }^{8}$

\section{Effect of different complex ligands on DNP}

In Fig. 3 we compared several different chelate complexes of $\mathrm{Gd}^{3+}$ as polarizing agents for ${ }^{1} \mathrm{H}$ and ${ }^{13} \mathrm{C}$ DNP at $140 \mathrm{GHz}$, recorded at a $\mu \mathrm{w}$ power level of $6 \mathrm{~W}$ (at probe input). There is a clear correlation between EPR line width of each complex and induced DNP enhancement (given as relative difference in relation to thermal polarization, i.e., $\varepsilon-1$ ) for ${ }^{1} \mathrm{H}$ and ${ }^{13} \mathrm{C}$, see Table 1. While for Gd-DOTA and $\mathrm{GdCl}_{3}$ (the latter exists as an aquo complex in aqueous solution $)^{89}$ the positive and negative ${ }^{1} \mathrm{H}$ SE legs are separated by a plateau area, they overlap for ${ }^{13} \mathrm{C}$ even for the complex with the smallest linewidth due to mutual overlap of the ZQ and DQ electron-nuclear transitions. Interestingly, for $\mathrm{GdCl}_{3}$ two components with starkly different
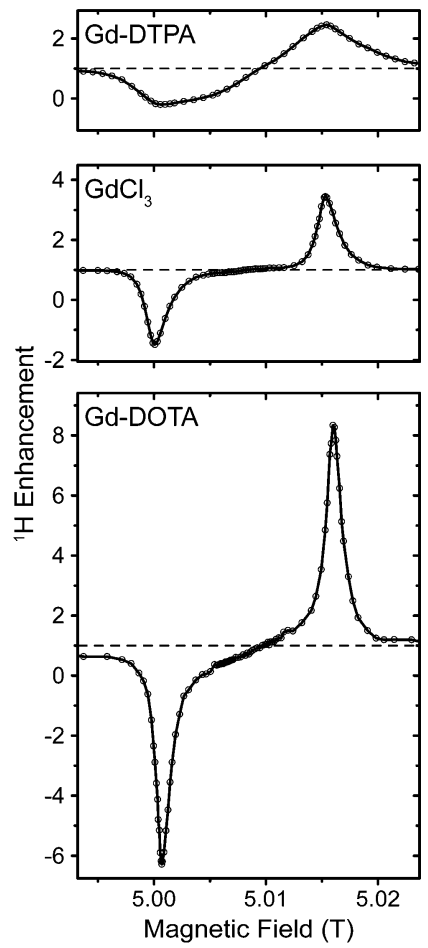
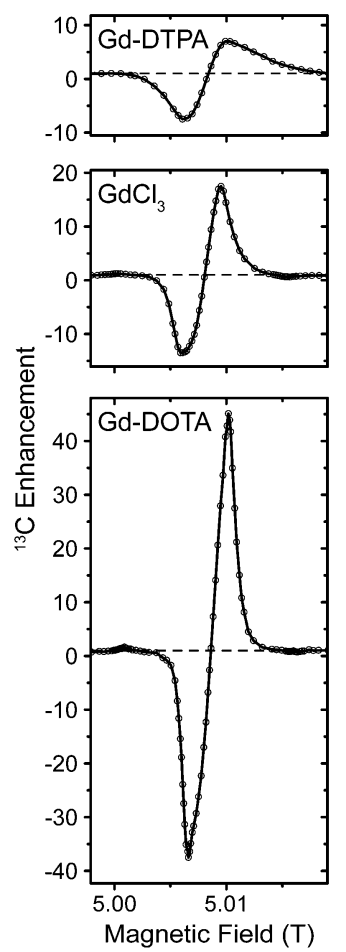

Fig. 3 Field dependent ${ }^{1} \mathrm{H}$ and ${ }^{13} \mathrm{C}$ DNP enhancement profiles of various Gd(III) complexes at $140 \mathrm{GHz}$.
Table 1 EPR and DNP properties of $10 \mathrm{mM} \mathrm{Gd(III)}$ complexes in ${ }^{13} \mathrm{C}_{3}$-glycerol $/ \mathrm{H}_{2} \mathrm{O}(60 / 40$ vol\%) at $5 \mathrm{~T}$

\begin{tabular}{|c|c|c|c|c|c|}
\hline \multirow[b]{2}{*}{ Complex } & \multicolumn{2}{|c|}{ ZFS parameters ${ }^{b}$} & \multirow[b]{2}{*}{$\begin{array}{l}\text { EPR linewidth } \\
(\mathrm{MHz})\end{array}$} & \multirow[b]{2}{*}{$\varepsilon_{\mathrm{H}}-1^{a}$} & \multirow[b]{2}{*}{$\varepsilon_{\mathrm{C}}-1^{a}$} \\
\hline & $D(\mathrm{MHz})$ & $\begin{array}{l}\Delta D \\
(\mathrm{MHz})\end{array}$ & & & \\
\hline Gd-DOTA & 672 & 336 & $30^{c}$ & $7.3(-7.3)$ & $44.0(-38.5)$ \\
\hline $\mathrm{GdCl}_{3}{ }^{d}$ & $\begin{array}{l}784 / 2184 \\
(1: 2.8)\end{array}$ & $448 / 952$ & $50^{c}$ & $2.5(-2.5)$ & $16.5(-14.5)$ \\
\hline Gd-DTPA & 1568 & 728 & $170^{c}$ & $1.5(-1.2)$ & $6.0(-8.5)$ \\
\hline \multicolumn{6}{|c|}{$\begin{array}{l}{ }^{a} \text { Measured at } \sim 6 \mathrm{~W} \mu \mathrm{w} \text { power; values given at the field of max. positive } \\
\text { enhancement, values in parentheses at field of max. magnitude of } \\
\text { negative enhancement. }{ }^{b} \text { From ref. } 90{ }^{c} \text { At } 5 \mathrm{~T} \text {, simulated from given } \\
\text { ZFS parameters. }{ }^{d} \text { Two components contributing to the spectrum with } \\
\text { relative weight given in parentheses. }\end{array}$} \\
\hline
\end{tabular}

ZFS parameters have been reported from EPR experiments. ${ }^{90}$ We do not observe such a biphasic behavior; however, our observations only seem to show a contribution from the component with smaller $D$ value. This might indicate that the complex species with large ZFS might not be effective as polarizing agent for DNP, or that its contribution to DNP is unproportionally small compared to the EPR contribution, as can also be seen by the $\sim$ 3-fold reduction in enhancement w.r.t. Gd-DOTA while the apparent linewidth only increases by $\sim 50 \%$.

${ }^{13} \mathrm{C}$ enhancements are significant, with $\sim 6-7$ times larger values than for ${ }^{1} \mathrm{H}$. For Gd-DTPA this ratio is somewhat smaller, however, in this case the magnitude of the negative enhancement is larger than that of the positive leg, most probably due to complicated overlap of SE transitions and other mechanisms leading to opposing DNP effects. We did not detect any sign of solid-state Overhauser effect (OE) as has been reported on BDPA radicals. ${ }^{8,34}$ Factors contributing to the OE in BDPA are the presence of significantly hyperfine-coupled ${ }^{1} \mathrm{H}$ and slow spin-lattice relaxation of the electron spin, both of which are less favorable in $\mathrm{Gd}^{3+}$ complexes.

Experiments using Mn-DOTA reveal a very similar situation; the main difference being the splitting of the rather narrow CT into an almost equally spaced sextet caused by hyperfine coupling to ${ }^{55} \mathrm{Mn}$ with a coupling constant of $254 \mathrm{MHz} .{ }^{37}$ This leads to a complicated system of six individual SE features evoked by each EPR line as is shown in Fig. 4. For ${ }^{1} \mathrm{H}$ these SE pairs are intricately intertwined due the ${ }^{1} \mathrm{H}$ nuclear Zeeman frequency being larger than half the ${ }^{55} \mathrm{Mn}$ HFI constant. For ${ }^{13} \mathrm{C}$ we encounter the opposite situation and each EPR line's SE pair is individually resolved. Furthermore, the small EPR linewidth now allows for almost complete separation of positive and negative enhancement legs with little-to-none mutual cancellation. NMR intensity comparisons between $\mu \mathrm{w}$-irradiation and non-irradiation allowed us to measure the enhancement factor for each EPR line (see red symbols in Fig. 4). Towards lower field slight deviations between the DNP-enhanced signal intensity and enhancement (obtained by on/off-comparison) occur which are due to lower efficiency of the spectrometer components (i.e., preamplifiers, filters, etc.). Nevertheless, for ${ }^{13} \mathrm{C}$ a symmetric variation of enhancement factors is observed which closely resembles the peak amplitude pattern of the EPR spectrum; for 

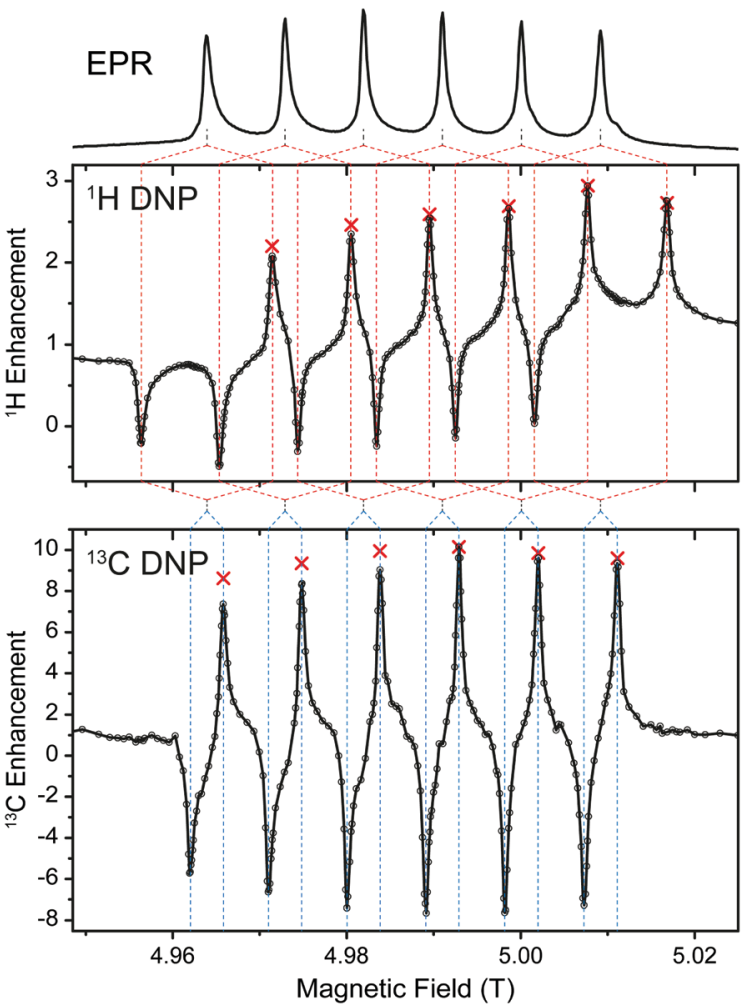

Fig. $4{ }^{1} \mathrm{H}$ (top graph) and ${ }^{13} \mathrm{C}$ (bottom graph) DNP of ${ }^{13} \mathrm{C}_{3}$-glycerol/ $/ \mathrm{H}_{2} \mathrm{O}$ (60/40 vol\%). Red crosses represent enhancement factors determined by explicit $\mu \mathrm{w}$ on $v s$. $\mu \mathrm{w}$ off measurements. Dashed lines serve as aides for correlation between EPR lines and DNP peaks.

${ }^{1} \mathrm{H}$ slight overlap of SE conditions lead to an asymmetric variation with larger enhancements obtainable for the second-tooutermost lines. Destructive interference occurs when $2 \omega_{0 I}=$ $n A\left({ }^{55} \mathrm{Mn}\right)$, where $\omega_{0 I}$ is the Larmor frequency of the nucleus to be enhanced, $A\left({ }^{55} \mathrm{Mn}\right)$ is the isotropic hyperfine coupling constant to the metal nucleus and $n$ is any integer between 1 and 5 . In such a case a positive enhancement peak is canceled by a negative peak of another HFI peak; however, the $n$ outermost (positive or negative) SE peaks are never canceled in such a way. Since peaks of equal sign cannot overlap, constructive interference of SE peaks is not possible. Nevertheless, when $\omega_{0 I}=$ $n A\left({ }^{55} \mathrm{Mn}\right)$, a $\mathrm{ZQ} / \mathrm{DQ}$ peak can be on resonance with a SQ transition of a another dipolar coupled $\mathrm{Mn}^{2+}$. This situation might lead to efficient CE matching, for example at a magnetic field of $11.7 \mathrm{~T}(500 \mathrm{MHz})$, where $\omega_{0 I}\left({ }^{1} \mathrm{H}\right) \approx 2 A\left({ }^{55} \mathrm{Mn}\right)$, and will be subject to further research.

\section{Influence of bulk protonation level}

For Gd-DOTA we investigated the effect of solvent deuteration level on ${ }^{13} \mathrm{C}$ DNP. Earlier studies have shown that slightly larger enhancement factors and faster polarization build-up can be achieved without matrix deuteration, in stark contrast to radical polarizing agents. ${ }^{35}$ Here, we record a $\sim 13 \%$ larger enhancement of ${ }^{13} \mathrm{C}$ for full protonation-with a maximum positive enhancement of 70 - compared to 62 for typically utilized $12 \%$ protonation within "DNP juice" (i.e., 60/30/10 vol\% mixture of $\mathrm{D}_{8}$-glycerol $/ \mathrm{D}_{2} \mathrm{O} / \mathrm{H}_{2} \mathrm{O}$ )

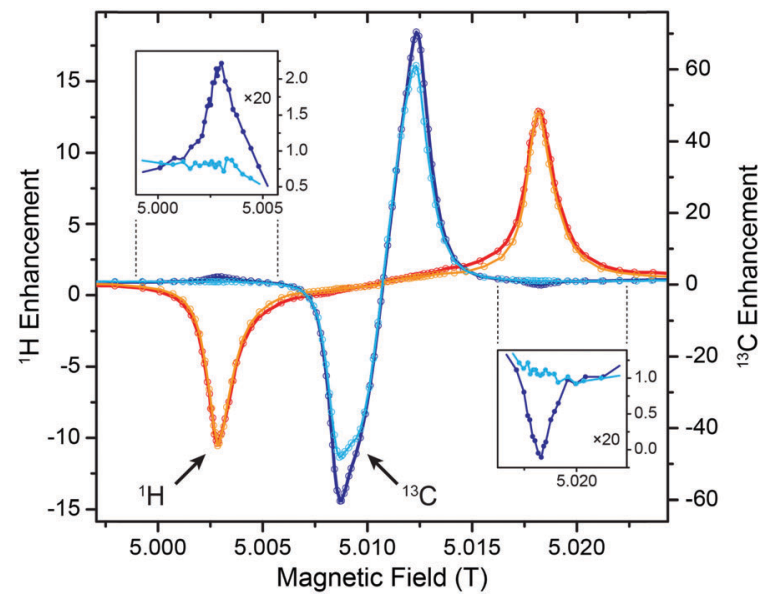

Fig. 5 Proton level dependence of ${ }^{1} \mathrm{H}$ (red) and ${ }^{13} \mathrm{C}$ (blue) DNP at $140 \mathrm{GHz}$ using Gd-DOTA as polarizing agent. Darker profiles are recorded on ${ }^{13} \mathrm{C}_{3}$-glycerol/ $/ \mathrm{H}_{2} \mathrm{O}\left(60 / 40\right.$ vol\%) as solvent, lighter profiles on $\left[\mathrm{D}_{8},{ }^{13} \mathrm{C}_{3}\right]$ glycerol $/ \mathrm{D}_{2} \mathrm{O} / \mathrm{H}_{2} \mathrm{O}(60 / 30 / 10$ vol\%). The insets show 20 -fold vertical magnifications of ${ }^{13} \mathrm{C}$ enhancements in the respective field region where ${ }^{1} \mathrm{H}$ SE condition is matched.

even though a slight broadening of the peaks within the field profile is visible (Fig. 5). This might be caused due to improved protondriven spin diffusion and/or longer build-up and longitudinal relaxation time constants. A complete overview of ${ }^{1} \mathrm{H}$ and ${ }^{13} \mathrm{C}$ enhancements at various protonation levels can be found in the $\mathrm{ESI} \dagger$ in Table S2.

An interesting effect occurs at the fields of most efficient (positive or negative) ${ }^{1} \mathrm{H}$ enhancement. Here, we see a small, but significant ${ }^{13} \mathrm{C}$ DNP enhancement of inverse sign with respect to ${ }^{1} \mathrm{H}$. The effect is observed with a fully protonated sample and does not occur with low ${ }^{1} \mathrm{H}$ levels (see below and Fig. 5). Possible multi-spin flips, where ${ }^{1} \mathrm{H}$ and ${ }^{13} \mathrm{C}$ are excited at the same time are theoretically and experimentally expected, but would occur at offsets of nuclear combination frequencies with respect to the SQ (EPR) frequency. ${ }^{91,92}$ We do not observe any splitting or shift of these features with respect to the ${ }^{1} \mathrm{H}$ SE peaks. Therefore, we attribute this effect to heteronuclear cross relaxation. ${ }^{1} \mathrm{H}$ populations-driven away from thermal equilibrium by SE DNP-may enhance ${ }^{13} \mathrm{C}$ in a similar way to the classical nuclear Overhauser effect (NOE). Due to relaxation from a hyperpolarized state instead of simple saturation this would result in opposite sign of ${ }^{13} \mathrm{C}$ enhancement with respect to that of ${ }^{1} \mathrm{H}$. Similar effects have been reported in samples after dissolution where molecular tumbling provides the required dynamics for relaxation. ${ }^{93}$ In our case it is unclear which dynamical process enables this relaxation process in the solid. The reader should note that the effect is rather weak ( $\sim 2 \%$ of maximum cross-relaxation enhancement); therefore even absolutely small variation of spectral density at the required sum and difference of nuclear Larmor frequencies might suffice for the observed effect to occur.

\section{Power dependence of DNP enhancement}

The power dependence of DNP enhancements is perfectly linear in most cases, as seen in Table 2 and shown in Fig. S1 (ESI $\dagger$ ). 
Interestingly, the DNP efficiency which is given by polarization increase of the nucleus relative to the theoretical maximum is almost identical for ${ }^{1} \mathrm{H}$ and ${ }^{13} \mathrm{C}$; consequently enhancement factors scale inversely with the nuclear gyromagnetic factor. ${ }^{13} \mathrm{C}$ DNP power dependence with Gd-DOTA shows a slight reduction of slope with larger power compared to the $\mathrm{Mn}^{2+}$ complex. The 'relayed' DNP enhancement of ${ }^{13} \mathrm{C}$ caused by $\mu \mathrm{w}$ excitation at the field of ${ }^{1} \mathrm{H}$ SE seems to indicate a more significant 'saturation' effect at larger powers, the reason for this is still unclear.

Also, a slight reduction of polarization time constant with increasing $\mu \mathrm{w}$ power is noticed (see Table 2). This trend is expected for $\mathrm{SE},{ }^{41}$ and has been already observed for trityl on the same instrument where we have also experimentally excluded sample heating as the major cause. ${ }^{35}$

Furthermore, in order to assess the achievable DNP enhancement in the excess of $\mu \mathrm{w}$ field strength we have investigated a static sample inside a $\mu \mathrm{w}$ cavity resonator driven by low-power solid-state source. With this instrument a typical $Q$ factors on the order of $\sim 1000$ leads to an effective nutation frequency of $\sim 16 \mathrm{MHz}$ for the CT of the $S=7 / 2 \mathrm{spin}$; this allows for significant ${ }^{1} \mathrm{H}$ DNP enhancement of $>100$ as we have reported earlier. ${ }^{84}$ Direct DNP of ${ }^{13} \mathrm{C}$ under irradiation of the ${ }^{13} \mathrm{C}$ SE transition leads to large absolute intensity of the enhanced NMR signal of ${ }^{13} \mathrm{C}_{3}$-glycerol, see Fig. S2 (ESI $\dagger$ ). Due to the large $\mu \mathrm{w}$ field strength available we reach a near-saturation condition already at $\sim 60 \%$ $\mu \mathrm{w}$ power; nevertheless a further reduction in polarization build-up time constant provides further sensitivity gains. A similar situation occurs for ${ }^{1} \mathrm{H}$ DNP at lower temperature. ${ }^{84}$ Unfortunately, we have been unable to measure the ${ }^{13} \mathrm{C}$ enhancement factor because no signal could be observed without $\mu$ w irradiation; analysis of the noise level allows us to provide a lower bound of $\varepsilon$ of 400 . For comparison we performed ${ }^{13} \mathrm{C} \mathrm{CP}$ experiment with ${ }^{1} \mathrm{H}$ DNP enhancement (by irradiation at the ${ }^{1} \mathrm{H}$ SE condition). We observe a 2.8 -fold larger intensity of the direct polarization (DP) spectrum, indicating that the large, direct ${ }^{13} \mathrm{C}$ SE enhancement easily overcompensates the up to 4-fold signal increase which can be achieved by ${ }^{1} \mathrm{H}$ DNP and subsequent CP transfer to ${ }^{13} \mathrm{C}$. Reduced CP efficiency due to the inhomogeneously broadened resonances and the presence of the paramagnetic polarizing agent cannot completely be neglected. Nevertheless, considering the larger signal intensity of the non-DNP-enhanced CP spectrum with respect to the DP spectrum, it is clear that CP efficiency $>1$. We therefore conclude that for ${ }^{13} \mathrm{C}, \varepsilon \geq 400$, with estimated factors of
800-1000 being much more likely. Enhancement factors of $>700$ have been observed for $30 \mathrm{mM}$ trityl solution by Banerjee et al. at 3.4 $\mathrm{T}$ but otherwise similar conditions. ${ }^{7}$ Our observations indicate that very large enhancement factors can be observed with sufficient $\mu \mathrm{w}$ field strength which makes Gd-DOTA a promising target for further investigations under these conditions.

Reduction of temperature has been shown to be more favorable, leading to larger enhancement factors already with smaller $\mu \mathrm{w}$ power. ${ }^{84}$ However, below a certain temperature (14 $\mathrm{K}$ at $5 \mathrm{~T}$ and increasing with larger fields) the depopulation of excited magnetic spin states of the $S=7 / 2$ system leads to reduced absolute population difference of the CT, rendering high-spin systems inactive as polarizing agents at low temperatures where $k_{\mathrm{B}} T<\gamma B_{0}$. This situation could be alleviated by the employment of sophisticated adiabatic sweep or pulse schemes which are able to transfer population from the highly polarized ground state transition into the DNP-enabling CT. ${ }^{10,94}$

\section{Field dependence of ${ }^{1} \mathrm{H}$ DNP}

$5 \mathrm{~T}$ is an ideal testbed for DNP experiments due to its instrumental robustness in terms of magnet sweep capability and $\mu \mathrm{w}$ power availability in combination with rather straightforward scalability of results to higher fields. Nevertheless, experiments at the commercially accessible fields of 9.4 and $14.1 \mathrm{~T}$ are important to confirm predictions based on lower field experiments and might also yield unexpected observations. Therefore we conducted ${ }^{1} \mathrm{H}$ DNP experiments using Gd-DOTA at these fields (Fig. 6). As expected, the matching field offset for positive and negative SE enhancement scale with the nuclear Larmor frequency and become more separated at higher field. Additionally, slight reduction in linewidth of the DNP peaks is observed with larger external field. This narrowing manifests when comparing the field dependence with that reported for BDPA, ${ }^{8}$ where at $9.4 \mathrm{~T}$ a slightly larger $\varepsilon$ was observed than for Gd-DOTA, however, at 14.1 $\mathrm{T}$ this ratio is inverse. Therefore we expect, that Gd-DOTA would significantly outperform BDPA at $18.8 \mathrm{~T}$ (reaching only vanishing $\varepsilon \approx 2$ ).

The narrowing is less pronounced than would be expected from the $B_{0}{ }^{-1}$ dependence of the second-order ZFS. In fact a considerable amount of dipolar broadening of the Gd(III) EPR spectrum occurs within the $10 \mathrm{mM}$ Gd-DOTA solution; when comparing DNP peak widths we found a reduction from 34.0 (30.8) $\mathrm{MHz}$ to 22.6 (22.0) $\mathrm{MHz}$ at 9.4 (14.1) $\mathrm{T}$ by lowering the Gd-DOTA concentration from 10 to $1 \mathrm{mM}$; we discuss this

Table 2 DNP properties of $10 \mathrm{mM}$ Gd-DOTA in ${ }^{13} \mathrm{C}_{3}$-glycerol/water $\left(60 / 40\right.$ vol\%) at various ${ }^{1} \mathrm{H}$ concentrations at $5 \mathrm{~T}(140 \mathrm{GHz})$

\begin{tabular}{|c|c|c|c|c|c|c|c|c|}
\hline $\begin{array}{l}\text { Solvent } \mathrm{D}_{8} \text {-glyc./ } \mathrm{H}_{8} \text {-glyc. }+ \\
\mathrm{D}_{2} \mathrm{O} / \mathrm{H}_{2} \mathrm{O}(\text { vol } \%)\end{array}$ & $\begin{array}{l}{ }^{1} \mathrm{H} \text { conc. } \\
\left(\mathrm{mol} \mathrm{L}^{-1}\right)\end{array}$ & $\begin{array}{l}{ }^{1} \mathrm{H} \text { ratio } \\
(\%)\end{array}$ & $\varepsilon^{(\mathrm{H})} 5 / 9 / 14 \mathrm{~W}$ & $\begin{array}{l}T_{1}^{(\mathrm{H})}(\mathrm{s}) \\
\text { no } \mu \mathrm{w}\end{array}$ & $T_{\mathrm{B}}^{(\mathrm{H})}(\mathrm{s}) 5 / 9 / 14 \mathrm{~W}$ & $\varepsilon^{(\mathrm{C}) a} 5 / 9 / 14 \mathrm{~W}$ & $T_{1}^{(\mathrm{C})}(\mathrm{s})$ no $\mu \mathrm{w}$ & $T_{\mathrm{B}}^{(\mathrm{H})}(\mathrm{s}) 5 / 9 / 14 \mathrm{~W}$ \\
\hline $0 / 60+0 / 40$ & $111.9^{a}$ & 100 & 8/13/19 & 3.2 & $3.1 / 3.0 / 2.8$ & $45 / 71 / 103$ & 86 & $85 / 83 / 80$ \\
\hline $60 / 0+30 / 10$ & $13.0^{a}$ & 12 & $8 / 13 / 18$ & 5.2 & $5.1 / 5.1 / 5.0$ & $41 / 61 / 91$ & 55 & $52 / 50 / 48$ \\
\hline $60 / 0+40 / 0$ & $\sim 1.6^{a}$ & $\sim 1.4$ & $5 / 8 / 12$ & 12 & $12 / 14 / 13$ & $41 / 64 / 93$ & 51 & $50 / 49 / 48$ \\
\hline
\end{tabular}

Multiple values separated by slashes given for different $\mu \mathrm{w}$ power levels of 5, 9, and $14 \mathrm{~W}$ (measured at probe entrance). ${ }^{a}$ Estimated from solvent composition. ${ }^{b}$ Not measured. 

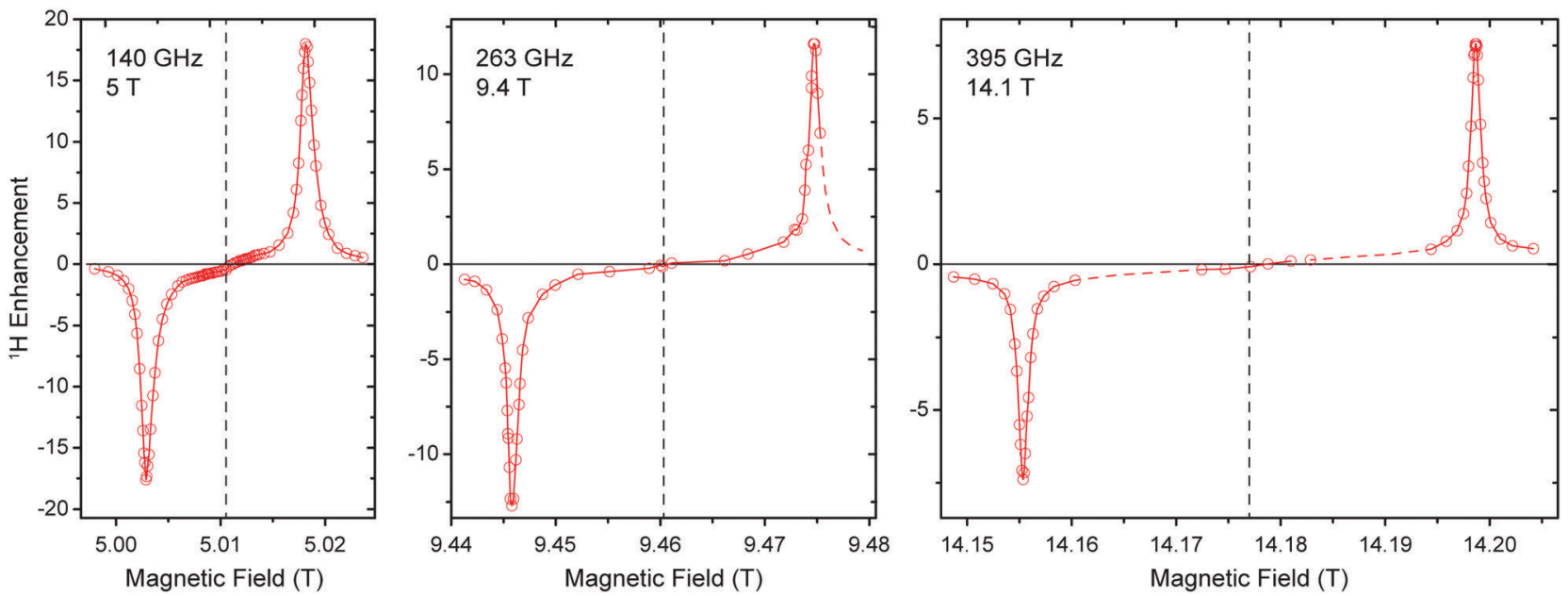

Fig. 6 Comparison between field-dependent ${ }^{1} \mathrm{H}$ DNP profiles of $10 \mathrm{mM} \mathrm{Gd-DOTA}$ in $\mathrm{D}_{8}$-glycerol/ $\mathrm{D}_{2} \mathrm{O} / \mathrm{H}_{2} \mathrm{O}(60: 30: 10$ vol\%) at 140,263 , and $395 \mathrm{GHz} \mu \mathrm{W}$ frequency. The EPR resonance fields are marked with dashed lines.

broadening in detail below. Nevertheless, we want to emphasize that a linewidth of $22 \mathrm{MHz}$ at $395 \mathrm{GHz}$ Larmor frequency corresponds to only $56 \mathrm{ppm}$, which is exceptionally small for a metal complex. For comparison, typical low-spin complex ions such as $\mathrm{Cu}^{2+}$ feature $g$ anisotropy of $\sim 20 \%$.

Power dependence and build-up dynamics at 9.4 and $14.1 \mathrm{~T}$ are both similar to what we observed at $5 \mathrm{~T}$. With larger $\mu \mathrm{w}$ power the ${ }^{1} \mathrm{H}$ enhancement shows a nearly linear increase at all fields; build-up times become slightly longer at higher field $(\sim 3 \mathrm{~s}$ at $5 \mathrm{~T}, \sim 4 \mathrm{~s}$ at $9.4 \mathrm{~T}, \sim 5 \mathrm{~s}$ at $14.1 \mathrm{~T})$.

\section{Effect of inter-complex couplings on direct DNP of ${ }^{13} \mathrm{C}$ and ${ }^{15} \mathrm{~N}$}

Stimulated by the observed broadening of the DNP field profiles above, we have performed a detailed analysis of DNP enhancements of ${ }^{1} \mathrm{H},{ }^{13} \mathrm{C}$, and ${ }^{15} \mathrm{~N}$ in comparison with EPR spectra for Gd-DOTA concentrations between 2 and $20 \mathrm{mM}$ at a $\mu \mathrm{w}$ frequency of $263 \mathrm{GHz}$ and a field of 9.4 T (Fig. 7). Due to technical reasons the DNP magnet used could only be swept slightly past the EPR resonance field of the $\mathrm{CT}$, therefore we were only able to record the negative enhancement of all nuclei except ${ }^{15} \mathrm{~N}$. Note the reduced EPR linewidth compared to $5 \mathrm{~T}$ (15 MHz vs. $25 \mathrm{MHz}$ ) due to the less pronounced second-order ZFS acting on the CT. This narrowing in combination with larger separation of the electron-nuclear ZQ and DQ transitions leads to positive and negative ${ }^{13} \mathrm{C}$ SE legs being now fully separated. A similar central plateau region occurs as seen for ${ }^{1} \mathrm{H}$ at $5 \mathrm{~T}$ because of similar ratios between nuclear Zeeman frequency and inhomogeneous linewidth. Even for ${ }^{15} \mathrm{~N}$ we observe the occurrence of a distinctive reduction of slope around the inflection point between the positive and negative legs, indicative of nearly complete separation of opposing enhancement regions. This is - to our knowledge-the first example of a well-resolved SE profile for such a low- $\gamma$ nucleus reported in literature.

The SE field profile can relatively simply be approximated by an approach based on the EPR spectral shape. Superposition of modeled ZQ and DQ peaks (i.e., by shifting the EPR spectral function by the field corresponding to the nuclear Zeeman frequency) of opposite sign allows for generation of a simulated SE DNP profile: ${ }^{11}$

$$
G_{\mathrm{SE}}\left(B_{0}\right)=G_{\mathrm{EPR}}\left(B_{0}-\omega_{0 I_{n}} / \gamma_{S}\right)-G_{\mathrm{EPR}}\left(B_{0}+\omega_{0 I_{n}} / \gamma_{S}\right),
$$

where $G\left(B_{0}\right)$ is the spectral shape function of SE DNP profile or the EPR spectrum. These simulations are shown as solid lines in Fig. 7B. At a low concentration of $2 \mathrm{mM}$ such an approximation generated from cw EPR spectra recorded at the same frequency of $263 \mathrm{GHz}$ show excellent congruence with experimental DNP enhancement factors. We have observed that simulated field profile based on cw EPR spectra match the experimental DNP profiles much more closely than those based on pulsed (field-swept, echo-detected) EPR spectra; in the latter case broader spectral components with short phase-memory time constant are filtered out, but obviously still contribute to DNP. When increasing the Gd-DOTA concentration to 10 or even $20 \mathrm{mM}$ we observe an incipient mismatch between EPR spectra and DNP profiles. For ${ }^{1} \mathrm{H}$ and $10 \mathrm{mM}$ the DNP peak and the EPR spectrum still show good agreement, while at $20 \mathrm{mM}$ a significant broadening of the DNP peak is visible. The reason for this is unclear and requires further experiments for elucidation.

For ${ }^{13} \mathrm{C}$ we observe an additional shoulder emerging in the DNP profile on the inner side of the negative SE peak, decreasing in magnitude with a constant slope towards the central inflection point. In the case of ${ }^{15} \mathrm{~N}$ the effect is even more pronounced; leading to a shift of the field of max. DNP enhancement towards the CT. Interestingly, we have succeeded in fitting the latter feature (see dashed lines in Fig. 7B) using a different approach based on a CE-type matching probability analysis: ${ }^{11}$

$$
\begin{aligned}
G_{\mathrm{CE}}\left(B_{0}\right)= & G_{\mathrm{EPR}}\left(B_{0}-\omega_{0 I_{n}} / \gamma_{S}\right) \times G_{\mathrm{EPR}}\left(B_{0}\right) \\
& -G_{\mathrm{EPR}}\left(B_{0}+\omega_{0 I_{n}} / \gamma_{S}\right) \times G_{\mathrm{EPR}}\left(B_{0}\right)
\end{aligned}
$$

Here, we determine the statistical probability of finding a pair of EPR resonances fulfilling the CE matching condition $\Delta \omega_{\mathrm{L}}=\omega_{0 I_{n}}$. For ${ }^{15} \mathrm{~N}$ DNP using $20 \mathrm{mM}$ Gd-DOTA there is an excellent agreement between such a simple simulation and experimental data indicating a relatively large contribution of CE besides SE. 
A

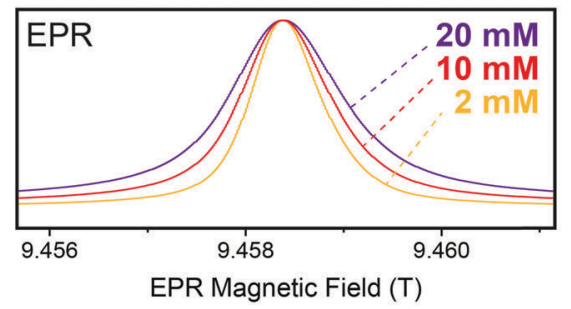

B
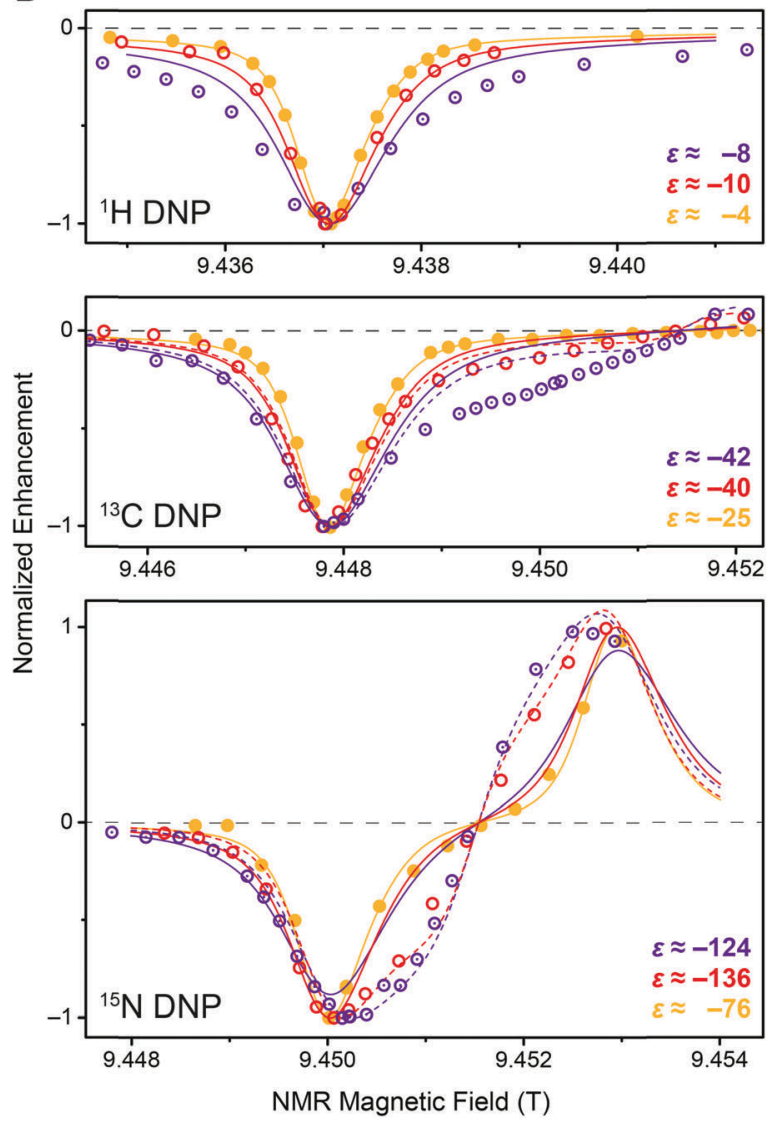

Fig. 7 (A) EPR spectra of $2 \mathrm{mM}$ (orange), $10 \mathrm{mM}$ (red), and $20 \mathrm{mM}$ (purple) Gd-DOTA at $263 \mathrm{GHz}$. Curves were obtained by simulating experimental CW (field-modulated) EPR spectra using Easyspin ${ }^{95}$ in order to avoid artifacts by integration. (B) Normalized DNP enhancement of ${ }^{1} \mathrm{H},{ }^{13} \mathrm{C}$, and ${ }^{15} \mathrm{~N}$ at $263 \mathrm{GHz}$ at $2 \mathrm{mM}$ (filled circles), $10 \mathrm{mM}$ (open circles), and $20 \mathrm{mM}$ (dotted open circles). Solid lines represent SE simulations according to eqn (1); dashed lines CE simulations according to eqn (2). Enhancement factors given are taken at field of maximum magnitude enhancement.

This is due to the inhomogeneous broadening allowing energyconserving CE transitions within the CT which is not possible for nuclei with larger gyromagnetic ratio. The large Gd(III) concentration provides for sufficient electron-electron couplings. Based on a statistical model ${ }^{96}$ the average nearest-neighbor distance amongst $\mathrm{Gd}^{3+}$ is $\sim 2.4 \mathrm{~nm}$ at $20 \mathrm{mM}$ concentration, yielding a dipole coupling constant of $\sim 3.8 \mathrm{MHz}$ at this distance. At $10 \mathrm{mM}$ the average distance increases to $3.0 \mathrm{~nm}(1.9 \mathrm{MHz})$; significant $\mathrm{CE}$ contribution is visible, albeit less pronounced. At $2 \mathrm{mM}$ no contribution of $\mathrm{CE}$ can be found due to vanishing dipolar coupling at the average distance of $5.2 \mathrm{~nm}(0.4 \mathrm{MHz})$. Even though we have not succeeded in reproducing the asymmetric feature of the ${ }^{13} \mathrm{C}$ profile with this simple model we tentatively ascribe the occurrence to a similar cause. We assume that-due to operation of the ${ }^{13} \mathrm{C} \mathrm{CE}$ outside of the $\mathrm{CT}-$ more complicated dependences on mutual orientations between neighboring Gd-DOTA and potential selection of highly CE-supportive pairs inhibit the application of such a simple model as eqn (2), whereas for ${ }^{15} \mathrm{~N}$ efficient mixing of the relevant states within the CT leads to CE irrespective of the orientation of the molecular frame. ${ }^{83}$

\section{Observation of enhanced polarization spreading by spin-diffusion}

When directly polarizing ${ }^{13} \mathrm{C}$ or ${ }^{15} \mathrm{~N}$ of isotope-labeled urea using $20 \mathrm{mM}$ Gd-DOTA through the glycerol/water matrix depleted in ${ }^{13} \mathrm{C}$ we observe an interesting behavior: while for very short polarization times the NMR signal shows significant homogeneous broadening, this broadening is reduced when more time is available for enhanced polarization to build up as can be seen in Fig. S3 (ESI $\dagger$ ). We explain this with a nonuniform spatial distribution of nuclear polarization where large enhancement is quickly generated for nuclei in close proximity to the paramagnetic ion. For polarization to spread further out towards less paramagnetically influenced nuclei spins, spin-diffusion has to occur through the bulk. Due to the small concentration of ${ }^{13} \mathrm{C}$ and ${ }^{15} \mathrm{~N}$ with an average nearest-neighbor distance of $\sim 0.5 \mathrm{~nm}$, spin diffusion constants are small and we observe overall build-up time constants on the order of $\sim 400 \mathrm{~s}$ and $\sim 1000 \mathrm{~s}$ for bridging the distance of $\sim 2.4 \mathrm{~nm}$ between polarizing agent centers. A complete set of build-up time constants for ${ }^{13} \mathrm{C}$ and ${ }^{15} \mathrm{~N}$ at various Gd-DOTA concentrations is given in Table 3. Our experiments here also confirm an earlier observations, where we had measured through-bulk build-up time constants in excess of $5000 \mathrm{~s}$ even for ${ }^{13} \mathrm{C}$ when both the urea and polarizing agent concentration were considerably smaller. ${ }^{42}$

\section{DNP with Gd(III) chelate tags attached to protein}

In a series of preliminary experiments we attached $\mathrm{Gd}^{3+}$ binding chelator tags to ubiquitin using site-directed spin labeling. Ubiquitin is an excellent model system due to typically large overexpression efficiency, and biochemical robustness under different environmental conditions. Furthermore, spinlabeled ubiquitin could potentially be utilized as a protein tag targeting other proteins in larger complexes via ubiquitylation for site-selective DNP applications, a route we plan to investigate in the near future.

We carried out experiments using three different single-site mutations of ubiquitin where in each case one cysteine residue was introduced by mutagenesis. We selected phenylalanine F4, alanine A28, as well as glycine G75 as favorable targets for mutation because these sites possess large surface accessibility and are situated in differing secondary structure elements (i.e., beta sheet, alpha helix, and terminal loop, respectively). Furthermore, the varying flexibility of the sites (e.g., G75 being situated in the flexible C-terminal tail region) might lead to 
Table 3 DNP properties of Gd-DOTA at various concentrations in ${ }^{12} \mathrm{C}_{3}$-glycerol/ $/ \mathrm{H}_{2} \mathrm{O}$ at $9.4 \mathrm{~T}(263 \mathrm{GHz})$

\begin{tabular}{lrllllllllll}
\hline $\left.\begin{array}{l}c_{\mathrm{Gd}-\mathrm{DOTA}} \\
(\mathrm{mol} \mathrm{L}\end{array}{ }^{-1}\right)$ & $\varepsilon^{(\mathrm{H})}$ & $\begin{array}{l}T_{\mathrm{B}}{ }^{(\mathrm{H})} \\
(\mathrm{s})\end{array}$ & $\varepsilon^{(\mathrm{C})}$ & $\begin{array}{l}T_{\mathrm{B}, \mathrm{f}}^{(\mathrm{C}) a} \\
(\mathrm{~s})\end{array}$ & $\begin{array}{l}T_{\mathrm{B}, \mathrm{s}}^{(\mathrm{C})} \\
(\mathrm{s})\end{array}$ & $\varphi^{(\mathrm{C}) c}$ & $\varepsilon^{(\mathrm{N})}$ & $\begin{array}{l}T_{\mathrm{B}, \mathrm{f}}^{(\mathrm{N}) a} \\
(\mathrm{~s})\end{array}$ & $\begin{array}{l}T_{\mathrm{B}, \mathrm{s}}^{(\mathrm{N}) b} \\
(\mathrm{~s})\end{array}$ & $\varphi^{(\mathrm{N}) c}$ \\
\hline 2 & -4 & 17 & -25 & 1213 & 3471 & 0.314 & -76 & 296 & 2990 & 0.198 \\
10 & -10 & 4.6 & -40 & $-{ }_{d}$ & $-{ }_{d}$ & $-{ }_{d}$ & -136 & $-{ }_{d}$ & $-{ }_{d}$ & $-{ }_{d}$ \\
20 & -8 & 2.2 & -42 & 113 & 396 & 0.351 & -124 & 114 & 1003 & 0.721
\end{tabular}

${ }^{a}$ Fast component of bi-exponential build-up. ${ }^{b}$ Slow component of bi-exponential build-up. ${ }^{c}$ Ratio between contribution of fast and slow component to overall signal as described by Wenk et $a .^{42}{ }^{d}$ Not measured.

different conformational inhomogeneity during freezing. 4MMDPA and DOTA-M were chosen as promising chelator tags as described by Goldfarb and co-workers. ${ }^{63,67}$

In Fig. 8 we show the direct DNP-enhancement of ${ }^{13} \mathrm{C}$ within uniformly $\left[{ }^{13} \mathrm{C},{ }^{15} \mathrm{~N}\right]$-labeled A28C ubiquitin mutant with each attached $\mathrm{Gd}(\mathrm{III}) \mathrm{tag}$, a comparison with the direct polarization ${ }^{13} \mathrm{C}$ MAS NMR spectrum of unlabeled A28C, the chemical structures of the tags and a model of the protein showing the single point mutation sites investigated. Within these preliminary experiments we have observed a rather small ${ }^{13} \mathrm{C}$ DNP enhancement by $\mathrm{Gd}^{3+} \mathrm{SE}$ on the order between approximately -1 to -3 when $\left[\mathrm{D}_{8},{ }^{12} \mathrm{C}_{3}\right]$-glycerol/ $\mathrm{D}_{2} \mathrm{O}$ mixture was used as solvent. We have not been able to observe significant differences between the different mutation sites so far. We assume that intra-molecular spin diffusion is sufficiently fast within the uniformly ${ }^{13} \mathrm{C}$-labeled protein, so that any variation in DNP efficiency is averaged after a few seconds of longitudinal magnetization build-up. Depletion of ${ }^{13} \mathrm{C}$ in the matrix below natural abundance strongly attenuates intermolecular spin-diffusion so that enhanced polarization is mostly maintained within the protein also carrying the $\mathrm{Gd}(\mathrm{III})$ polarization source as we have demonstrated with endogenously bound $\mathrm{Mn}^{2+} .42$

DNP enhancements are larger and build-up times are faster for Gd-4MMDPA labeled protein. EPR spectra of the Gd-labeled proteins at the same frequency $(263 \mathrm{GHz})$ show a $\sim 2$ times larger linewidth of the CT in 4MMDPA as in DOTA-M caused by the lower symmetry and larger ZFS in the former complex (Fig. S4, ESI $\dagger$ ). Therefore we would also expect lower efficiency of DNP according to Fig. 3 in this case. The opposite finding is likely explained by the shorter tether between chelator moiety and protein. We observe significant broadening of ${ }^{13} \mathrm{C}$ resonances especially with Gd-4MMDPA due to similar reasons. Also, upon $\mu \mathrm{w}$ irradiation and hence DNP enhancement ( $\mu \mathrm{w}$ on), additional broadening occurs as compared to the spectra acquired using thermal polarization ( $\mu \mathrm{w}$ off). All these observations indicate more favorable DNP enhancement of ${ }^{13} \mathrm{C}$ nuclei in close distance to the paramagnetic ion.

We have determined labeling efficiencies between $90 \%$ (for 4MMDPA) and $100 \%$ (for DOTA-M) by cw EPR spin counting; both values can be interpreted as quantitative within the experimental error. Therefore we assume that a significant contribution of unlabeled protein-which could lead to similar observations-is rather unlikely. Due to the rather short
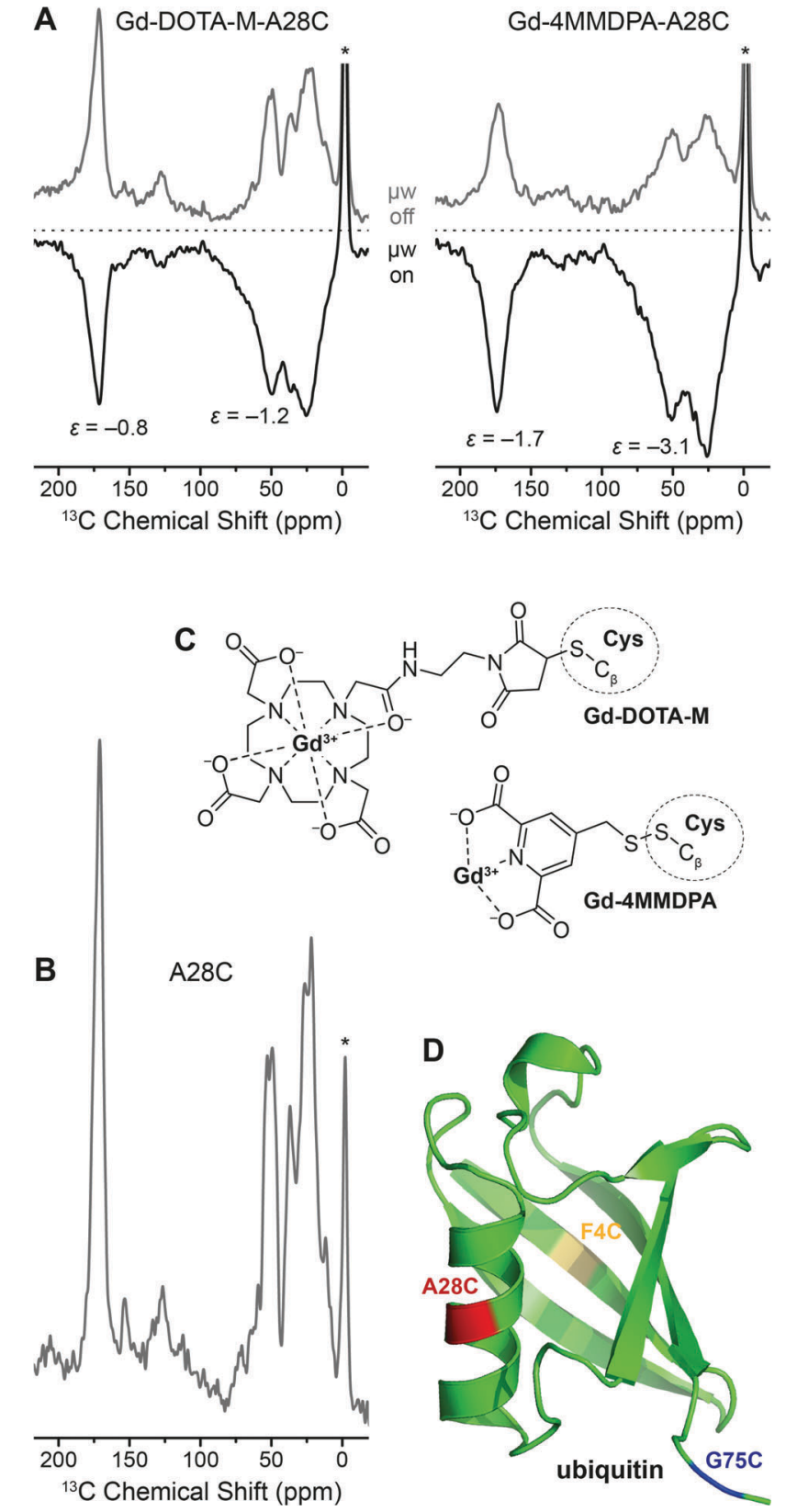

Fig. 8 (A) Direct ${ }^{13} \mathrm{C}$ DNP enhancement of uniformly $\left[{ }^{13} \mathrm{C},{ }^{15} \mathrm{~N}\right]$-labeled ubiquitin mutant $\mathrm{A} 28 \mathrm{C}$ using site-directed spin labeling with $\mathrm{Gd}$-DOTA-M and $\mathrm{Gd}-4 \mathrm{MMDPA}$ tags at 9.4 T. The field was optimized for $\mathrm{Gd}^{3+}{ }^{13} \mathrm{C}$ SE resulting in negative signal enhancement. Read-out was performed via Bloch decay with 6 and 2.3 s polarization delay, respectively. (B) ${ }^{13} \mathrm{C}$ MAS spectrum of $\mathrm{A} 28 \mathrm{C}$ ubiquitin (without attached spin label), read-out via Bloch decay and $16 \mathrm{~s}$ polarization delay. Asterisks mark signals from silicone plugs. (C) Chemical structures of Gd-4MMDPA and Gd-DOTA-M spin labels connected to cysteine residues. (D) Ribbon structure of ubiquitin (PDB ID 1UBQ) with F4C, A28C, and G75C single-site mutations marked in yellow, red, and blue, respectively.

spin-lattice relaxation of ${ }^{13} \mathrm{C}$ in the fully protonated (diamagnetic) protein with $T_{1_{n}}$ of about $10 \mathrm{~s}$ we expect the enhancement to drastically improve upon deuteration (fully or selectively of methyl-carrying amino acids); such experiments are currently pursued. 


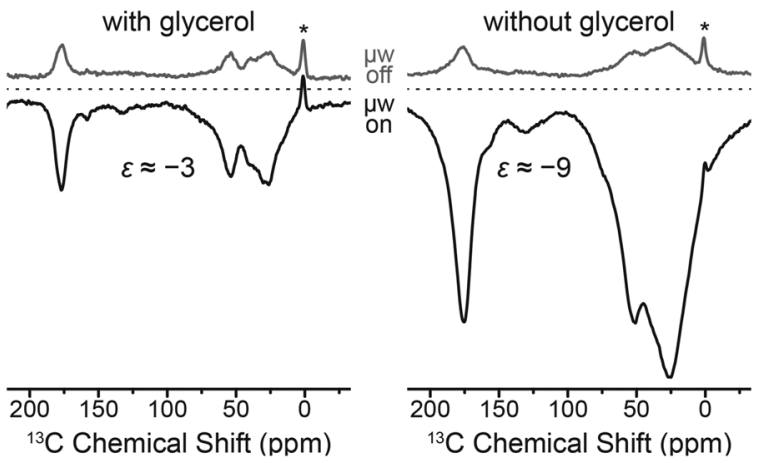

Fig. 9 Direct DNP enhancement of uniformly $\left[{ }^{13} \mathrm{C},{ }^{15} \mathrm{~N}\right]$-labeled ubiquitin mutant $\mathrm{F} 4 \mathrm{C}$ with and without added glycerol using site-directed spin labeling with Gd-DOTA-M tags at 9.4 T. The field was optimized for $\mathrm{Gd}^{3+}{ }^{13} \mathrm{C}$ SE resulting in negative signal enhancement. Read-out was performed via Bloch decay with $4 \mathrm{~s}$ polarization delay. Asterisks mark signals from silicone plugs.

An unexpected phenomenon was observed when the cryoprotectant was absent from the aqueous buffer solution. Since the paramagnetic label is covalently attached to the biomolecule, separation of the polarizing agent and protein in different phases-which reportedly inhibits $\mathrm{DNP}^{51}$ - cannot occur. DNP enhancement factors improved three-fold to about -9 while at the same time strong line broadening occurs. This is shown in Fig. 9 on the F4C mutant labeled with Gd-DOTA-M; we have observed very similar effects with other point mutation/chelate tag combinations as well. We explain this by agglomeration of paramagnetically labeled ubiquitins and hence a local increase in Gd(III) concentration. This is supported by shorter build-up time constants in the cryoprotectant-free samples.

Of course, the increase in linewidth in the small globular protein due to the presence of Gd3+ complicates the extraction of structural information in the typical way. However, such approaches might be fruitful with respect to specifically labeled proteins or ligands where spectral resolution is less important, or for problems in larger biomolecular systems where, for example, contacts between subunits are of interest. In fact, the occurrence of additional polarization pathways-including $\mathrm{CE}$ enabled by direct dipolar contact between $\mathrm{Gd}^{3+}$ of different proteins-bears an interesting prospect for future studies including multiply-labeled proteins and singly-labeled subunits within protein complexes, enabling efficient CE only upon direct contact of their constituents. Similar concepts have been demonstrated with nitroxides. ${ }^{56}$ This could allow for filtering towards a minority of bound species in co-existence next to the majority of unbound components; a situation which poses a significant problem in biophysical chemistry or structural biology.

\section{Conclusion}

While the indirect enhancement of ${ }^{13} \mathrm{C}$ NMR spectra via ${ }^{1} \mathrm{H}$ DNP using complexes of $\mathrm{Gd}^{3+}$ and $\mathrm{Mn}^{2+}$ has already been demonstrated in principle, ${ }^{37}$ we have now extended the investigation especially for direct ${ }^{13} \mathrm{C}$ DNP. ${ }^{1} \mathrm{H}$ DNP enhancements of up to 20 have been measured which are yet unable to compete with those factors obtained by more efficient bis-nitroxide polarizing agents on model systems. However, paramagnetic metal ions still offer various other interesting properties especially in the context of biomolecular DNP. We have shown that deuteration of the matrix-which is rather difficult in cellular milieu-is not required because it does not lead to larger enhancement factors in model systems. Furthermore, many biomolecules are routinely investigated with paramagnetic NMR using lanthanide probes where paramagnetic relaxation enhancements (PREs) and pseudocontact shifts (PCSs) are analyzed for structural constraints in solution. ${ }^{80,97}$ MAS DNP could be able to contribute additional information without further modification of the sample. This is especially interesting in regards to highly efficient direct DNP of ${ }^{13} \mathrm{C}$ or ${ }^{15} \mathrm{~N}$ with enhancement factors of $\sim 100$ and larger. While at low polarizing agent concentrations SE is the dominating DNP mechanism for these nuclei, at large concentrations we observed a significant contribution of the CE which is achieved by electron spin frequency offsets caused by ZFS.

Direct DNP of low- $\gamma$ nuclei allows for a better control of spreading of enhanced polarization due to small spin-diffusion rates in environments with small isotope concentration. Furthermore, we have demonstrated in preliminary experiments that proteins labeled with $\mathrm{Gd}^{3+}$-binding chelator tags could themselves be used as polarizing agents. This approach could in the future be extended in order to investigate protein-protein interactions, allowing enhanced polarization to spread from one domain to another only when a close contact is maintained.

\section{Acknowledgements}

P. Gast (Leiden University) has kindly acquired the $275 \mathrm{GHz}$ EPR spectra. Access to the 9.4 and $14.1 \mathrm{~T}$ DNP spectrometers has been generously provided by Bruker Biospin (Billerica, MA) for acquisition of data presented in Fig. 6. All other data at 9.4 T has been measured at Technical University Darmstadt with access provided by G. Buntkowsky and technical support from T. Gutmann. V. Denysenkov (Frankfurt) has helped with the acquisition of $263 \mathrm{GHz}$ EPR spectra. We acknowledge help from F. Sochor (Frankfurt) regarding protein expression and J. Knauer (Frankfurt) for synthesis of 4MMDPA, for which A. Heckel (Frankfurt) has kindly provided laboratory space. We thank M. Reese (formerly MIT) for helpful discussions. RGG acknowledges funding by the National Institutes of Health (NIH) projects EB-002026 and EB-002804. BC has been funded by the Deutsche Forschungsgemeinschaft (DFG) through Emmy Noether grant CO802/2-1. RS is funded by a DFG research fellowship (SI2105/1-1). BC and HS acknowledge financial and technical support as well as spectrometer access from the Center for Biomolecular Magnetic Resonance (BMRZ).

\section{References}

1 D. A. Hall, D. C. Maus, G. J. Gerfen, S. J. Inati, L. R. Becerra, F. W. Dahlquist and R. G. Griffin, Science, 1997, 276, 930-932. 
2 L. R. Becerra, G. J. Gerfen, R. J. Temkin, D. J. Singel and R. G. Griffin, Phys. Rev. Lett., 1993, 71, 3561-3564.

3 G. J. Gerfen, L. R. Becerra, D. A. Hall, R. G. Griffin, R. J. Temkin and D. J. Singel, J. Chem. Phys., 1995, 102, 9494-9497.

4 V. S. Bajaj, M. K. Hornstein, K. E. Kreischer, J. R. Sirigiri, P. P. Woskov, M. L. Mak-Jurkauskas, J. Herzfeld, R. J. Temkin and R. G. Griffin, J. Magn. Reson., 2007, 189, 251-279.

5 K. N. Hu, G. T. Debelouchina, A. A. Smith and R. G. Griffin, J. Chem. Phys., 2011, 134, 19.

6 E. A. Chekhovich, M. N. Makhonin, A. I. Tartakovskii, A. Yacoby, H. Bluhm, K. C. Nowack and L. M. K. Vandersypen, Nat. Mater., 2013, 12, 494-504.

7 D. Banerjee, D. Shimon, A. Feintuch, S. Vega and D. Goldfarb, J. Magn. Reson., 2013, 230, 212-219.

8 T. V. Can, M. A. Caporini, F. Mentink-Vigier, B. Corzilius, J. J. Walish, M. Rosay, W. E. Maas, M. Baldus, S. Vega, T. M. Swager and R. G. Griffin, J. Chem. Phys., 2014, 141, 064202.

9 Y. Hovav, A. Feintuch and S. Vega, J. Magn. Reson., 2010, 207, 176-189.

10 I. Kaminker, A. Potapov, A. Feintuch, S. Vega and D. Goldfarb, Phys. Chem. Chem. Phys., 2009, 11, 6799-6806.

11 D. Shimon, Y. Hovav, A. Feintuch, D. Goldfarb and S. Vega, Phys. Chem. Chem. Phys., 2012, 14, 5729-5743.

12 K. R. Thurber and R. Tycko, J. Chem. Phys., 2012, 137, 084508.

13 F. Mentink-Vigier, Ü. Akbey, Y. Hovav, S. Vega, H. Oschkinat and A. Feintuch, J. Magn. Reson., 2012, 224, 13-21.

14 D. Mance, P. Gast, M. Huber, M. Baldus and K. L. Ivanov, J. Chem. Phys., 2015, 142, 234201.

15 A. S. Lilly Thankamony, C. Lion, F. Pourpoint, B. Singh, A. J. Perez Linde, D. Carnevale, G. Bodenhausen, H. Vezin, O. Lafon and V. Polshettiwar, Angew. Chem., Int. Ed., 2015, 54, 2190-2193.

16 D. Lee, G. Monin, N. T. Duong, I. Z. Lopez, M. Bardet, V. Mareau, L. Gonon and G. De Paëpe, J. Am. Chem. Soc., 2014, 136, 13781-13788.

17 A. Lesage, M. Lelli, D. Gajan, M. A. Caporini, V. Vitzthum, P. Miéville, J. Alauzun, A. Roussey, C. Thieuleux, A. Mehdi, G. Bodenhausen, C. Copéret and L. Emsley, J. Am. Chem. Soc., 2010, 132, 15459-15461.

18 P. Wolf, M. Valla, A. J. Rossini, A. Comas-Vives, F. NúñezZarur, B. Malaman, A. Lesage, L. Emsley, C. Copéret and I. Hermans, Angew. Chem., Int. Ed., 2014, 53, 10179-10183.

19 L. Zhao, W. Li, A. Plog, Y. Xu, G. Buntkowsky, T. Gutmann and K. Zhang, Phys. Chem. Chem. Phys., 2014, 16, 26322-26329.

20 T. Gutmann, J. Liu, N. Rothermel, Y. Xu, E. Jaumann, M. Werner, H. Breitzke, S. T. Sigurdsson and G. Buntkowsky, Chem. - Eur. J., 2015, 21, 3798-3805.

21 M. Rosay, J. C. Lansing, K. C. Haddad, W. W. Bachovchin, J. Herzfeld, R. J. Temkin and R. G. Griffin, J. Am. Chem. Soc., 2003, 125, 13626-13627.

22 M. L. Mak-Jurkauskas, V. S. Bajaj, M. K. Hornstein, M. Belenky, R. G. Griffin and J. Herzfeld, Proc. Natl. Acad. Sci. U. S. A., 2008, 105, 883-888.

23 V. S. Bajaj, M. L. Mak-Jurkauskas, M. Belenky, J. Herzfeld and R. G. Griffin, Proc. Natl. Acad. Sci. U. S. A., 2009, 106, 9244-9249.
24 A. B. Barnes, B. Corzilius, M. L. Mak-Jurkauskas, L. B. Andreas, V. S. Bajaj, Y. Matsuki, M. L. Belenky, J. Lugtenburg, J. R. Sirigiri, R. J. Temkin, J. Herzfeld and R. G. Griffin, Phys. Chem. Chem. Phys., 2010, 12, 5861-5867. 25 G. T. Debelouchina, M. J. Bayro, A. W. Fitzpatrick, V. Ladizhansky, M. T. Colvin, M. A. Caporini, C. P. Jaroniec, V. S. Bajaj, M. Rosay, C. E. MacPhee, M. Vendruscolo, W. E. Maas, C. M. Dobson and R. G. Griffin, J. Am. Chem. Soc., 2013, 135, 19237-19247.

26 L. B. Andreas, A. B. Barnes, B. Corzilius, J. J. Chou, E. A. Miller, M. Caporini, M. Rosay and R. G. Griffin, Biochemistry, 2013, 52, 2774-2782.

27 I. Gelis, V. Vitzthum, N. Dhimole, M. Caporini, A. Schedlbauer, D. Carnevale, S. Connell, P. Fucini and G. Bodenhausen, J. Biomol. NMR, 2013, 56, 85-93.

28 E. J. Koers, E. A. W. van der Cruijsen, M. Rosay, M. Weingarth, A. Prokofyev, C. Sauvée, O. Ouari, J. van der Zwan, O. Pongs, P. Tordo, W. E. Maas and M. Baldus, J. Biomol. NMR, 2014, 60, 157-168.

29 Y. Su, L. Andreas and R. G. Griffin, Annu. Rev. Biochem., 2015, 84, 465-497.

30 A. Potapov, W.-M. Yau, R. Ghirlando, K. R. Thurber and R. Tycko, J. Am. Chem. Soc., 2015, 137, 8294-8307.

31 L. R. Becerra, G. J. Gerfen, B. F. Bellew, J. A. Bryant, D. A. Hall, S. J. Inati, R. T. Weber, S. Un, T. F. Prisner, A. E. McDermott, K. W. Fishbein, K. E. Kreischer, R. J. Temkin, D. J. Singel and R. G. Griffin, J. Magn. Reson., Ser. A, 1995, 117, 28-40.

32 C. Song, K.-N. Hu, C.-G. Joo, T. M. Swager and R. G. Griffin, J. Am. Chem. Soc., 2006, 128, 11385-11390.

33 T. Maly, A. F. Miller and R. G. Griffin, ChemPhysChem, 2010, 11, 999-1001.

34 O. Haze, B. Corzilius, A. A. Smith, R. G. Griffin and T. M. Swager, J. Am. Chem. Soc., 2012, 134, 14287-14290.

35 B. Corzilius, A. A. Smith and R. G. Griffin, J. Chem. Phys., 2012, 137, 054201.

36 V. K. Michaelis, A. A. Smith, B. Corzilius, O. Haze, T. M. Swager and R. G. Griffin, J. Am. Chem. Soc., 2013, 135, 2935-2938.

37 B. Corzilius, A. A. Smith, A. B. Barnes, C. Luchinat, I. Bertini and R. G. Griffin, J. Am. Chem. Soc., 2011, 133, 5648-5651.

38 K. N. Hu, H. H. Yu, T. M. Swager and R. G. Griffin, J. Am. Chem. Soc., 2004, 126, 10844-10845.

39 C. Sauvée, M. Rosay, G. Casano, F. Aussenac, R. T. Weber, O. Ouari and P. Tordo, Angew. Chem., Int. Ed., 2013, 52, 10858-10861.

40 J. H. Ardenkjær-Larsen, I. Laursen, I. Leunbach, G. Ehnholm, L. G. Wistrand, J. S. Petersson and K. Golman, J. Magn. Reson., 1998, 133, 1-12.

41 A. A. Smith, B. Corzilius, A. B. Barnes, T. Maly and R. G. Griffin, J. Chem. Phys., 2012, 136, 015101.

42 P. Wenk, M. Kaushik, D. Richter, M. Vogel, B. Suess and B. Corzilius, J. Biomol. NMR, 2015, 63, 97-109.

43 M. Rosay, V. Weis, K. E. Kreischer, R. J. Temkin and R. G. Griffin, J. Am. Chem. Soc., 2002, 124, 3214-3215. 
44 T. Jacso, W. T. Franks, H. Rose, U. Fink, J. Broecker, S. Keller, H. Oschkinat and B. Reif, Angew. Chem., Int. Ed., 2012, 51, 432-435.

45 J. Becker-Baldus, C. Bamann, K. Saxena, H. Gustmann, L. J. Brown, R. C. D. Brown, C. Reiter, E. Bamberg, J. Wachtveitl, H. Schwalbe and C. Glaubitz, Proc. Natl. Acad. Sci. U. S. A., 2015, 112, 9896-9901.

46 P. C. A. van der Wel, K. N. Hu, J. Lewandowski and R. G. Griffin, J. Am. Chem. Soc., 2006, 128, 10840-10846.

47 G. T. Debelouchina, M. J. Bayro, P. C. A. van der Wel, M. A. Caporini, A. B. Barnes, M. Rosay, W. E. Maas and R. G. Griffin, Phys. Chem. Chem. Phys., 2010, 12, 5911-5919.

48 M. J. Bayro, G. T. Debelouchina, M. T. Eddy, N. R. Birkett, C. E. MacPhee, M. Rosay, W. E. Maas, C. M. Dobson and R. G. Griffin, J. Am. Chem. Soc., 2011, 133, 13967-13974.

49 A. J. Rossini, A. Zagdoun, F. Hegner, M. Schwarzwälder, D. Gajan, C. Copéret, A. Lesage and L. Emsley, J. Am. Chem. Soc., 2012, 134, 16899-16908.

50 T. Maly, D. Cui, R. G. Griffin and A.-F. Miller, J. Phys. Chem. $B, 2012,116,7055-7065$.

51 T.-C. Ong, M. L. Mak-Jurkauskas, J. J. Walish, V. K. Michaelis, B. Corzilius, A. A. Smith, A. M. Clausen, J. C. Cheetham, T. M. Swager and R. G. Griffin, J. Phys. Chem. B, 2013, 117, 3040-3046.

52 C. Fernández-de-Alba, H. Takahashi, A. Richard, Y. Chenavier, L. Dubois, V. Maurel, D. Lee, S. Hediger and G. De Paëpe, Chem. - Eur. J., 2015, 21, 4512-4517.

53 M. A. Voinov, D. B. Good, M. E. Ward, S. Milikisiyants, A. Marek, M. A. Caporini, M. Rosay, R. A. Munro, M. Ljumovic, L. S. Brown, V. Ladizhansky and A. I. Smirnov, J. Phys. Chem. B, 2015, 119, 10180-10190.

54 H. Takahashi, S. Hediger and G. De Paepe, Chem. Commun., 2013, 49, 9479-9481.

55 A. N. Smith, M. A. Caporini, G. E. Fanucci and J. R. Long, Angew. Chem., Int. Ed., 2015, 54, 1542-1546.

56 B. J. Wylie, B. G. Dzikovski, S. Pawsey, M. Caporini, M. Rosay, J. H. Freed and A. E. McDermott, J. Biomol. NMR, 2015, 61, 361-367.

57 E. A. W. van der Cruijsen, E. J. Koers, C. Sauvée, R. E. Hulse, M. Weingarth, O. Ouari, E. Perozo, P. Tordo and M. Baldus, Chem. - Eur. J., 2015, 21, 12971-12977.

58 V. M. Runge, R. G. Stewart, J. A. Clanton, M. M. Jones, C. M. Lukehart, C. L. Partain and A. E. James, Radiology, 1983, 147, 789-791.

59 J. A. Koutcher, C. T. Burt, R. B. Lauffer and T. J. Brady, J. Nucl. Med., 1984, 25, 506-513.

60 R. H. Knop, J. A. Frank, A. J. Dwyer, M. E. Girton, M. Naegele, M. Schrader, J. Cobb, O. Gansow, M. Maegerstadt, M. Brechbiel, L. Baltzer and J. L. Doppman, J. Comput. Assist. Tomogr., 1987, 11, 35-42.

61 P. Hermann, J. Kotek, V. Kubicek and I. Lukes, Dalton Trans., 2008, 3027-3047.

62 A. M. Raitsimring, C. Gunanathan, A. Potapov, I. Efremenko, J. M. L. Martin, D. Milstein and D. Goldfarb, J. Am. Chem. Soc., 2007, 129, 14138-14139.
63 A. Potapov, H. Yagi, T. Huber, S. Jergic, N. E. Dixon, G. Otting and D. Goldfarb, J. Am. Chem. Soc., 2010, 132, 9040-9048.

64 H. Yagi, D. Banerjee, B. Graham, T. Huber, D. Goldfarb and G. Otting, J. Am. Chem. Soc., 2011, 133, 10418-10421.

65 D. Banerjee, H. Yagi, T. Huber, G. Otting and D. Goldfarb, J. Phys. Chem. Lett., 2012, 3, 157-160.

66 D. T. Edwards, Z. Ma, T. J. Meade, D. Goldfarb, S. Han and M. S. Sherwin, Phys. Chem. Chem. Phys., 2013, 15, 11313-11326.

67 A. Martorana, G. Bellapadrona, A. Feintuch, E. Di Gregorio, S. Aime and D. Goldfarb, J. Am. Chem. Soc., 2014, 136, 13458-13465.

68 P. Lueders, G. Jeschke and M. Yulikov, J. Phys. Chem. Lett., 2011, 2, 604-609.

69 D. Akhmetzyanov, J. Plackmeyer, B. Endeward, V. Denysenkov and T. F. Prisner, Phys. Chem. Chem. Phys., 2015, 17, 6760-6766.

70 J. Eisinger, R. G. Shulman and W. E. Blumberg, Nature, 1961, 192, 963-964.

71 A. Cavé, M.-F. Daures, J. Parello, A. Saint-Yves and R. Sempere, Biochimie, 1979, 61, 755-765.

72 A. Dvoretsky, V. Gaponenko and P. R. Rosevear, FEBS Lett., 2002, 528, 189-192.

73 M. D. Vlasie, C. Comuzzi, A. M. C. H. van den Nieuwendijk, M. Prudêncio, M. Overhand and M. Ubbink, Chem. - Eur. J., 2007, 13, 1715-1723.

74 P. S. Nadaud, J. J. Helmus, S. L. Kall and C. P. Jaroniec, J. Am. Chem. Soc., 2009, 131, 8108-8120.

75 I. Sengupta, P. S. Nadaud, J. J. Helmus, C. D. Schwieters and C. P. Jaroniec, Nat. Chem., 2012, 4, 410-417.

76 W. R. Couet, R. C. Brasch, G. Sosnovsky and T. N. Tozer, Magn. Reson. Imaging, 1985, 3, 83-88.

77 S. Belkin, R. J. Mehlhorn, K. Hideg, O. Hankovsky and L. Packer, Arch. Biochem. Biophys., 1987, 256, 232-243.

78 I. Krstić, R. Hänsel, O. Romainczyk, J. W. Engels, V. Dötsch and T. F. Prisner, Angew. Chem., Int. Ed., 2011, 50, 5070-5074.

79 A. P. Jagtap, I. Krstic, N. C. Kunjir, R. Hänsel, T. F. Prisner and S. T. Sigurdsson, Free Radical Res., 2015, 49, 78-85.

80 G. Otting, Annu. Rev. Biophys., 2010, 39, 387-405.

81 C. D. Jeffries, Phys. Rev., 1960, 117, 1056-1069.

82 C. F. Hwang and D. A. Hill, Phys. Rev. Lett., 1967, 19, 1011-1014.

83 B. Corzilius, Phys. Chem. Chem. Phys., 2016, DOI: 10.1039/ c6cp04621e.

84 A. A. Smith, B. Corzilius, J. A. Bryant, R. DeRocher, P. P. Woskov, R. J. Temkin and R. G. Griffin, J. Magn. Reson., 2012, 223, 170-179.

85 H. Blok, J. A. J. M. Disselhorst, S. B. Orlinskii and J. Schmidt, J. Magn. Reson., 2004, 166, 92-99.

86 G. Mathies, H. Blok, J. A. J. M. Disselhorst, P. Gast, H. van der Meer, D. M. Miedema, R. M. Almeida, J. J. G. Moura, W. R. Hagen and E. J. J. Groenen, J. Magn. Reson., 2011, 210, 126-132.

87 A. B. Barnes, M. L. Mak-Jurkauskas, Y. Matsuki, V. S. Bajaj, P. C. A. van der Wel, R. DeRocher, J. Bryant, J. R. Sirigiri, 
R. J. Temkin, J. Lugtenburg, J. Herzfeld and R. G. Griffin, J. Magn. Reson., 2009, 198, 261-270.

88 C. D. Joye, R. G. Griffin, M. K. Hornstein, H. Kan-Nian, K. E. Kreischer, M. Rosay, M. A. Shapiro, J. R. Sirigiri, R. J. Temkin and P. P. Woskov, IEEE Trans. Plasma Sci., 2006, 34, 518-523.

89 C. Cossy, L. Helm, D. H. Powell and A. E. Merbach, New J. Chem., 1995, 19, 27-35.

90 A. M. Raitsimring, A. V. Astashkin, O. G. Poluektov and P. Caravan, Appl. Magn. Reson., 2005, 28, 281-295.

91 A. A. Smith, B. Corzilius, O. Haze, T. M. Swager and R. G. Griffin, J. Chem. Phys., 2013, 139, 214201.
92 D. Shimon, Y. Hovav, I. Kaminker, A. Feintuch, D. Goldfarb and S. Vega, Phys. Chem. Chem. Phys., 2015, 17, 11868-11883.

93 K. J. Donovan, A. Lupulescu and L. Frydman, ChemPhysChem, 2014, 15, 436-443.

94 A. Doll, S. Pribitzer, R. Tschaggelar and G. Jeschke, J. Magn. Reson., 2013, 230, 27-39.

95 S. Stoll and A. Schweiger, J. Magn. Reson., 2006, 178, 42-55.

96 S. Chandrasekhar, Rev. Mod. Phys., 1943, 15, 1-89.

97 K. Barthelmes, A. M. Reynolds, E. Peisach, H. R. A. Jonker, N. J. DeNunzio, K. N. Allen, B. Imperiali and H. Schwalbe, J. Am. Chem. Soc., 2011, 133, 808-819. 